This item was submitted to Loughborough's Research Repository by the author.

Items in Figshare are protected by copyright, with all rights reserved, unless otherwise indicated.

\title{
An assessment of the wear characteristics of microcutting arrays produced from polycrystalline diamond and cubic boron nitride composites
}

PLEASE CITE THE PUBLISHED VERSION

https://doi.org/10.1115/1.4030761

PUBLISHER

(C) ASME

VERSION

AM (Accepted Manuscript)

\section{PUBLISHER STATEMENT}

This work is made available according to the conditions of the Creative Commons Attribution-NonCommercialNoDerivatives 4.0 International (CC BY-NC-ND 4.0) licence. Full details of this licence are available at: https://creativecommons.org/licenses/by-nc-nd/4.0/

\section{LICENCE}

CC BY-NC-ND 4.0

\section{REPOSITORY RECORD}

Pacella, Manuela, D.A. Axinte, P.W. Butler-Smith, P.H. Shipway, M. Daine, and C. Wort. 2015. "An Assessment of the Wear Characteristics of Microcutting Arrays Produced from Polycrystalline Diamond and Cubic Boron Nitride Composites". Loughborough University. https://hdl.handle.net/2134/27723. 


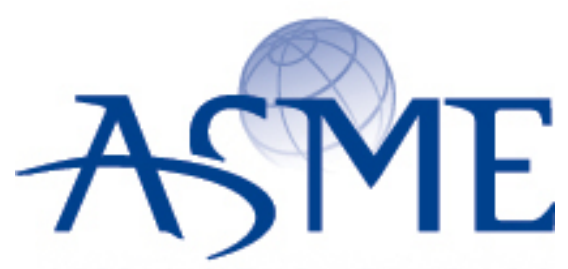

\section{American Society of Mechanical Engineers}

SETTING THE STANDARD

ASME Accepted Manuscript Repository

Institutional Repository Cover Sheet

ASME Paper Title: An assessment of the wear characteristics of microcutting arrays produced from polycrystalline

diamond and cubic boron nitride composites

Authors: $\quad$ M. Pacella, D. A. Axinte, P. W. Butler-Smith, P. Shipway, M. Daine and C. Wort

ASME Journal Title: J ournal of Manufacturing Science and Engineering

Date of Publication (VOR* Online) September 92015

Volume/Issue _138(2)

ASME Digital Collection URL: http://manufacturingscience.asmedigitalcollection.asme.org/article.aspx?articleid=2442367

DOI: $\quad 10.1115 / 1.4030761$

*VOR (version of record) 


\title{
An assessment of the wear characteristics of micro-cutting arrays produced from polycrystalline diamond and cubic boron nitride composites
}

\author{
M. Pacella, PhD \\ PhD Researcher \\ Faculty of Engineering, Machining and Condition Monitoring Research Group, \\ Manufacturing and Process Technologies Research Division \\ The University of Nottingham \\ University Park, Nottingham, NG7 2RD, United Kingdom \\ eaxmp1@nottingham.ac.uk \\ D. A. Axinte ${ }^{1}$, PhD \\ Professor \\ Faculty of Engineering, Machining and Condition Monitoring Research Group, \\ Manufacturing and Process Technologies Research Division \\ The University of Nottingham \\ University Park, Nottingham, NG7 2RD, United Kingdom \\ Dragos.Axinte@nottingham.ac.uk \\ P. W.Butler-Smith, PhD \\ Researcher \\ Faculty of Engineering, Machining and Condition Monitoring Research Group, \\ Manufacturing and Process Technologies Research Division \\ The University of Nottingham \\ University Park, Nottingham, NG7 2RD, United Kingdom \\ Paul.Butler-Smith@nottingham.ac.uk

\section{P. Shipway, PhD} \\ Professor \\ Faculty of Engineering, Materials, Mechanics and Structures Research Division \\ The University of Nottingham \\ University Park, Nottingham, NG7 2RD, United Kingdom \\ Philip.Shipway@nottingham.ac.uk
}

M. Daine

Research Technician

${ }^{1}$ Corresponding Author: Prof. D. A. Axinte 
Faculty of Engineering, Machining and Condition Monitoring Research Group, Manufacturing and Process Technologies Research Division

The University of Nottingham

University Park, Nottingham, NG7 2RD, United Kingdom

Mark.Daine@nottingham.ac.uk

\section{Wort}

Manager New Technologies

Element Six Ltd., Oxford, United Kingdom

chris.wort@e6.com

\section{ABSTRACT}

The current methods for manufacturing super-abrasive elements result in a stochastic geometry of abrasives with random three-dimensional abrasive locations. This paper focuses on the evaluation of wear progression /failure characteristics of micro-abrasive arrays made of ultra-hard composites (polycrystalline diamond - PCD; polycrystalline cubic boron nitride - $P C B N)$ in cutting/wear tests against Silicon dioxide workpiece. Pulsed laser ablation (Nd: YAG laser) has been used to manufacture repeatable patterns of micro-abrasive edges onto micro structurally different $P C D / P C B N$ composites. Opposing to these highlyengineered micro-abrasive arrays, conventional electroplated abrasive pads containing diamond and CBN abrasives respectively have been chosen as benchmarks and tested under the same conditions. Contact profiling, optical microscopy and environmental scanning electron microscopy have been employed for the characterisation of the abrasive arrays and electroplated tools before/during/after the wear/cutting tests. For the PCD abrasive micro-arrays, the type of grain and binder percentage proved to affect the wear performances due to the different extents of compressive stresses occurring at the grain boundaries. In this respect, the micro-arrays made of $P C D$ with mixed diamond grain sizes have shown slower wear progression when compared to the electroplated diamond pads confirming the combination of the high wear resistance typical of the fine grain and the good shock resistance typical of the coarse grain structures. The micro-arrays made of fine grained diamond abrasives have produced lower contact 
Journal of Manufacturing Science and Engineering, Transactions of the ASME

pressures with the workpiece shaft, confirming a possible application in polishing or grinding. As for the PCBN abrasive micro-arrays, the increase of metallic binder and the presence of metalloids in the medium content-CBN specimens have shown to produce higher contact pressure with the workpiece when compared to the electroplated specimen, causing fracturing as the main wear mechanism; while the PCBN micro-array with purely a metallic binder phase has shown slower wear and lower contact pressure in comparison to the electroplated CBN specimen. Among all of the tested arrays, the mixed grained PCD and the purely metallic binder phase PCBN micro-arrays have shown slower wear when benchmarked to the electroplated pads, giving a possible application of their use in the cutting tool industry.

\section{INTRODUCTION}

During the last decades, the use of ultra-hard materials in the cutting tool industry has facilitated enhanced precision and productivity in aerospace, automotive and woodworking industries [1]. Polycrystalline diamond (PCD) composites are suitable for cutting applications in light of their high thermal conductivity combined with hardness typical of PCD itself; in areas where the thermal stability of PCD results in tool failure (e.g. cutting of steels), composites based upon polycrystalline cubic boron nitride (PCBN), exhibiting high hardness simultaneously with thermal stability, could be more suitable [2]. In the case of abrasive tools, the typical cutting surfaces have a stochastic spatial distributions of the individual abrasive particles, with each particle itself having an uncontrolled orientation and geometry; the performances of such abrasive tools are difficult to control. However, it has been argued that an abrasive tool with repeatable and homogeneous distributed micro-features/abrasives not only facilitates the accommodation of grinding debris and aids heat transfer but also achieves consistent 
performance thereby improving the tool life [3], [4]. Accordingly, technologies to generate novel tools incorporating abrasive-like features but with controlled geometry and high repeatability offer a significant technological advance; the non-conventional shaping technique of laser ablation has been recognised as a versatile approach among the material removal technologies, and has been shown to be applicable to these ultrahard materials [5]. Laser ablation removes the workpiece material via a thermal process, making the generation of micro-features/cutting edges on ultra-hard materials (that are normally very difficult to generate with conventional machining processes) readily achievable [3]. In particular, laser micro-machining using high intensity, pulsed visible laser radiation, is capable of forming precise micro scale features in diamond in an efficient manner without showing significant surface damage [6]-[8]. The application of laser ablation to create repeatable micro-features onto single crystal diamond materials has been studied in relation to the tribological properties of the features for machining applications [3], [7]. The tribological characteristics are clearly related to both the geometry of the micro-cutting/polishing elements and the workpiece material utilised with the importance of the rake and clearance faces upon the performance of the abrasive edges of mono-crystalline CVD diamond micro-arrays patterned to provide chip flow during machining having been specifically demonstrated [3]. Laser ablation technology has been successfully used for the production of macro-features/edges for cutting inserts on ultra-hard materials with a variety of rake and clearance angles. The variation of the geometrical characteristics of the macro-cutting edges has been reported in literature: negative rake angles in the range $-6^{\circ} /-10^{\circ}$ are typically utilised for 
PCBN composites [9]-[12] while rake angles of circa $0^{\circ}$ have been used especially for single crystal diamond [13], [14]. While laser ablation has been widely employed for straight and profiled cutting of diamond [10], [11], there have not been many studies for generating geometrically controlled micro-features on flat and curved diamond surfaces until recently [7]. The possibility of control of the geometry of the abrasive edges (rake face, clearance face, sharpness of edge) represents an important requirement in machining/grinding with defined shapes of abrasives as this affects not only their performance but also the wear progression. Additionally, research on evaluating the wear characteristics of ultra-hard inserts against different workpiece materials (e.g. Ti64, Silicon Nitride, steel), demonstrated that the severity and mechanism of wear in ultra-hard tools really much vary with the type of material selected: in particular, testing PCD against steel can results in a quicker failure of the tool because of the chemical interaction between the two, while slower wear is shown on a PCBN tool when testing the same material [15], [16]. In all of the reported literature on the evaluation of the wear properties of PCD composites, it has been indicated that the extreme wear resistance of the composites renders standard wear testing procedures unsuitable [17], [18]. Despite this, the wear mechanisms of ultra-hard materials have been categorized into four groups: normal wear, chipping, chip dragging and fracture of the cutting edge [19]. It has been demonstrated that despite the edge quality being higher for a PCD with a finer grain size, the abrasion resistance is improved as the grain size is increased [1], [20]. Coarse grained PCDs are thus preferred under harsh conditions in light of their wear resistance, while fine grained PCDs are preferred when enhanced surface quality is 
required [1]. While there are still gaps in understanding the wear mechanism of ultrahard composite materials, several researchers have examined the wear performance of electroplated diamond abrasive tools; most of these have demonstrated a progressive increase in cutting forces and a dulling of the abrasives, and these have been attributed to attritious wear [2], [21], [22].

Due to its high hardness (second to diamond), polycrystalline cubic boron nitride (PCBN) has been used as cutting tool in hard turning of steel producing smooth (roughness, $0.95 \mu \mathrm{m}$ ) and uniform surfaces [9]. Five wear mechanisms have been identified for PCBN tool wear: abrasion, fatigue, adhesion, dissolution/diffusion and through tribochemical processes [23], [24]. It has been demonstrated that grades with lower fractions of CBN are useful in continuous and semi-interrupted machining (e.g. hard turning) because of their reduced flank wear; high $\mathrm{CBN}$-content grades tend to be more resistant to degradation in interrupted machining, but wear rapidly at higher cutting speeds [11]. The type of wear depends upon the continuity or interruption of the tool-workpiece contact as well as on the CBN percentage in the PCBN composite: abrasive wear has been found in continuous cutting conditions, while chipping was found as an addition to abrasion in the interrupted cutting [1], [9], [25]. Although there is a body of literature reporting on the performance of both low and high-CBN grades in conventional machining, no studies have addressed wear/cutting performance of these materials micro-textured in such a way that they can be employed in grinding-type operations. 
This study will address the mechanisms of wear of micro-abrasive edges in relation to the type of binder (metallic, ceramic), binder fraction, hard-phase type (PCD, PCBN) and grain size distribution in relation to the cutting/grinding applications. Specifically, it will address the wear/cutting performance of microstructurally different PCD and PCBN micro-abrasive edges produced via pulsed laser ablation as follows:

- Introduction of a new concept of abrasive tools in PCD/PCBN composites via a pulsed laser ablation (PLA) design/optimisation procedure. In particular, a novel concept of abrasive arrays composed of staggered micro-edges with ca. $6^{\circ}$ rake angle and ca. $30^{\circ}$ clearance angle is presented.

- Evaluation of the wear progression of the novel abrasive micro-arrays via wear/cutting tests against silicon dioxide shafts to prove their ability to remove material at low reaction forces with reduced degradation of cutting edges (i.e. demonstrating that this concept is viable in terms of tool wear characteristics).

- Analysis of time progression of the wear/cutting performances of microstructurally different PCD/PCBN abrasive micro-arrays against benchmarked electroplated diamond/CBN pads to understand the essential differences in their failure mechanisms and cutting performances.

\section{METHODOLOGY}

\subsection{Tool and workpiece materials}

A range of microstructurally different $P C D$-based and $P C B N$-based materials have been selected for the experiments in order to establish the influence of microstructural 
factors (e.g. binder phase fraction, crystal intergrowth, texture) of the composites in the wear progression of the micro-abrasive arrays and to allow their performance to be compared with conventional electroplated abrasive elements. Accordingly, two PCD thick films $(10 \mathrm{~mm} \times 10 \mathrm{~mm} \times 0.5 \mathrm{~mm})$ deposited onto a $1 \mathrm{~mm}$ thick WC-Co substrate layer have been chosen for the creation of the micro-abrasive arrays. Backscattered Electron Scanning Electron Microscope (ESEM) images of two polycrystalline diamond materials are presented in Fig. 1a - mixed grain (PCD CTM302, grain size 2-30 $\mu$ m, cobalt binder 10 vol\%) PCD composite and Fig. 1b - fine grain (PCD CMX850, grain size 0.5-1 $\mu \mathrm{m}$, cobalt binder 15 vol\%) PCD composite. In these images, the cobalt binder phase exhibits high contrast with the PCD being the lower contrast phase. The selection of various binder bulk volume percentages and different diamond grain size of PCD allows the relation between the microstructural factors typical of each material and their wear progression characteristics to be explored.

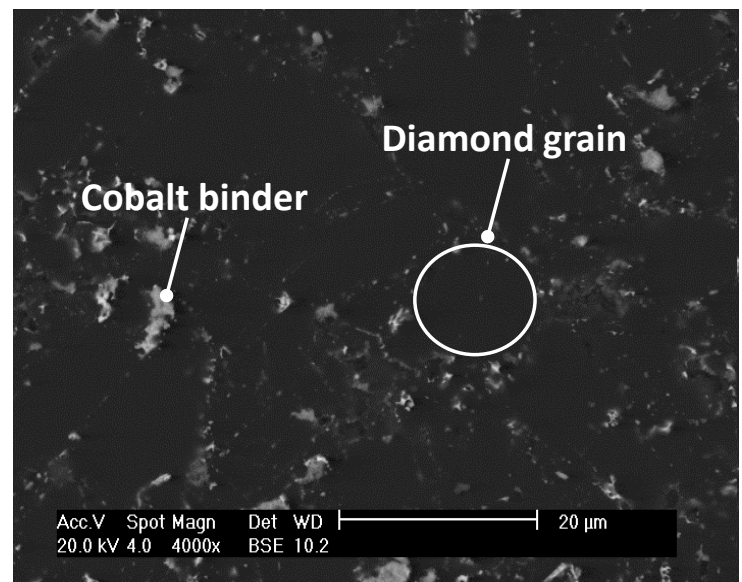

a)

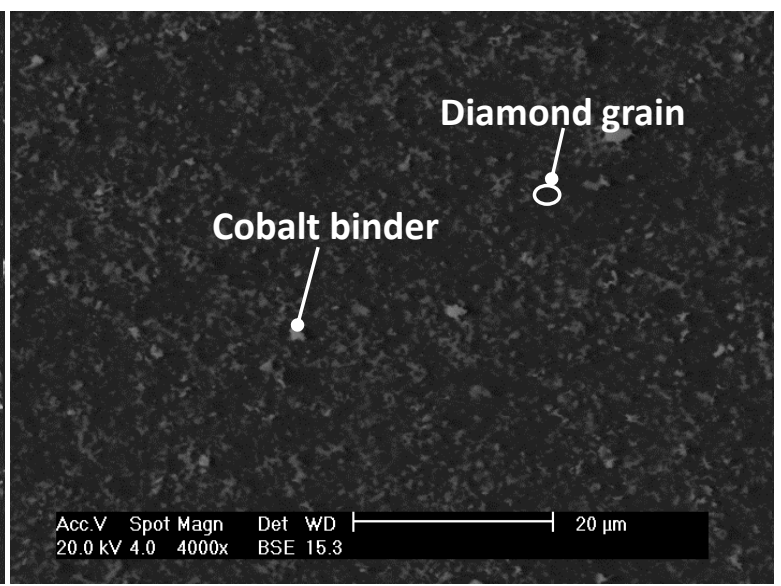

b)

Fig. 1: Backscattered ESEM images of polished surfaces of polycrystalline diamond: a) CTM302 mixed grained; b) CMX850 fine grained. 
Two grades of PCBN thick film $(10 \mathrm{~mm} \times 10 \mathrm{~mm} \times 0.5 \mathrm{~mm})$ directly synthesized onto a WC substrate layer $(1 \mathrm{~mm})$ have been selected as follows: high-CBN fraction (PCBN DBS900; CBN, average grain size 2-4 $\mu \mathrm{m}$; Co-Ni binder 10 vol\%) with a purely metallic binder phase (Fig. 2a), and a medium-CBN fraction (PCBN DBW85; CBN, average grain size 1-2 $\mu \mathrm{m}$; AIWCoB binder 15 vol\%) with a more complex metallic binder material, shown in Fig. $2 b$. DBW85 has proven [26] to be one of the most versatile high-CBN grades because of its excellent strength and abrasion resistance resulting in high chipping resistance making it widely used in interrupted cutting of a wide range of hard materials. DBS900 with up to 90 vol\% of CBN has been shown to be appropriate for applications where a long tool life is required [26].

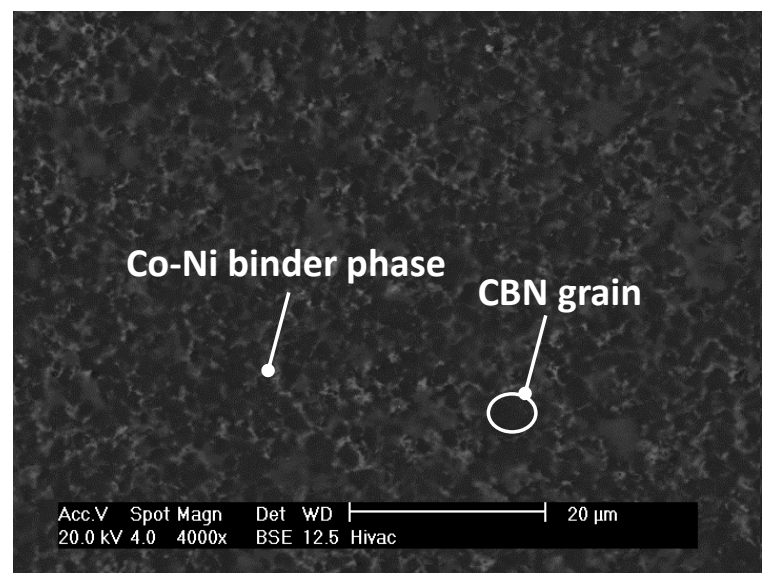

a)

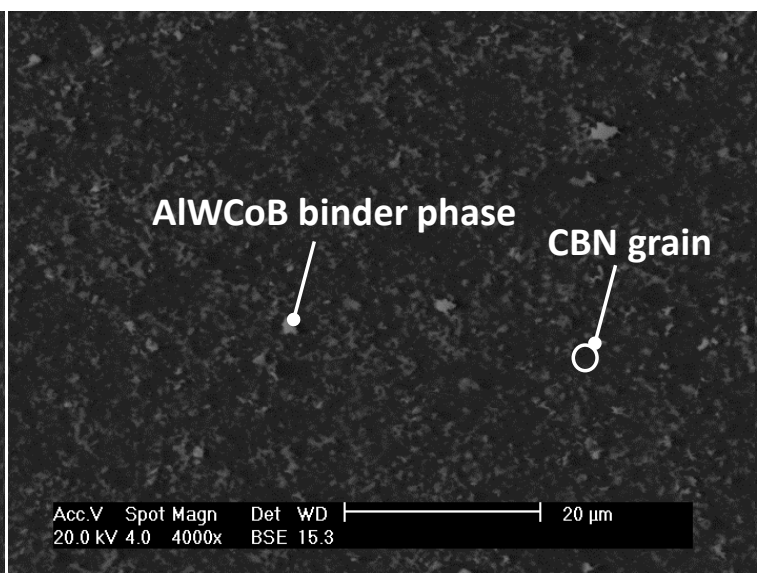

b)

Fig. 2: Backscattered ESEM images of polished surfaces of polycrystalline cubic boron nitride: a) DBS900 high-CBN content; b) DBW85 medium-CBN content.

It is important to mention that the machining characteristics (such as cutting condition and feed speed) together with the workpiece thermo-mechanical properties determine 
the wear mechanism and performances when utilising cutting edges of super-hard materials [27], [28]. Silicon oxide $\left(\mathrm{SiO}_{2}\right)$ composite shafts (diameter, $25 \mathrm{~mm}$; length, $50 \mathrm{~mm}$ ) have been selected as workpiece material for the wear/cutting test. The properties of amorphous $\mathrm{SiO}_{2}$ make it a suitable material to be tested against ultra-hard materials. Because of its lower fracture toughness $\left(0.7 \mathrm{MPa} \mathrm{m}^{1 / 2}\right)$ when compared to PCD and PCBN (see Table 1), it exhibits brittle machining behaviour [27]: this means that PCD/PCBN composites could exhibits not only the widely known mechanical wear mechanism (cracks in PCBN are driven by mechanical stress) but also a tribo-mechanical wear type mechanism that is more affected by the workpiece material and its chemical interaction/adhesion with the tool [30]. The $\mathrm{SiO}_{2}$ very low thermal conductivity (1.4 $\mathrm{Wm}^{-1} \mathrm{~K}^{-1}$ ) [34] makes it a suitable material for machining applications where the cutting condition of low thermally conductive materials (e.g. ceramics) can be replicated and enhanced [25]. When used against CBN tools the silicon dioxide is considered a difficult to machine material [32] offering the possibility of accelerated wear test. In fact, $\mathrm{SiO}_{2}$ high hardness may reduce the wear progression rate of the tested abrasive arrays and therefore allow the single steps of wear progression to be analysed and discussed [13].

Table 1 reports all of the measured values of hardness and fracture toughness for the tested materials based on previous research. 
Table 1: Hardness and fracture toughness for the tested materials [25], [33], [34].

\begin{tabular}{lll}
\hline Specimen & Hardness (GPa) & Fracture toughness $\left(\mathbf{M P a ~ m}^{\mathbf{1 / 2}}\right.$ ) \\
\hline PCD CTM302 & 64.0 & 15.0 \\
PCD CMX850 & $50.0-60.0$ & 13.2 \\
PCBN DBW85 & 40.7 & 6.4 \\
PCBN DBS900 & 36.0 & 7.6 \\
$\mathrm{SiO}_{2}$ & 35.4 & 0.7 \\
\hline
\end{tabular}

In order to benchmark the performances of the novel micro-abrasive arrays, two types of conventional electroplated abrasive pads $(10 \mathrm{~mm} \times 10 \mathrm{~mm} \times 0.5 \mathrm{~mm})$ have been selected for a comparative test: electroplated diamond abrasive (grade D501) pads - Fig. 3a; electroplated CBN abrasive (grade B501) - Fig. 3b. In both cases, the substrate material is tungsten carbide (thickness $1 \mathrm{~mm}$ ) and the bonding type is Nickel. The abrasives selected (graded to the Federation of European Producers of Abrasives (FEPA) standards) have an average nominal size of $500 \mu \mathrm{m}$ to provide a reasonable comparison with the dimensions of the micro-abrasive edges.

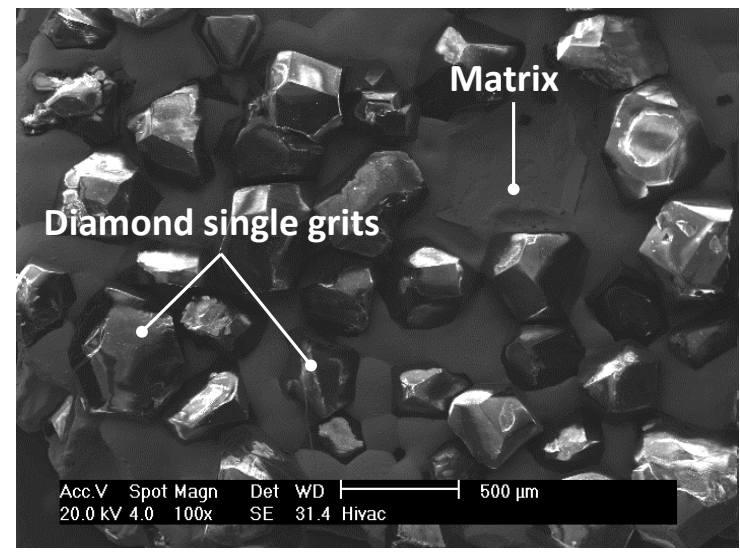

a)

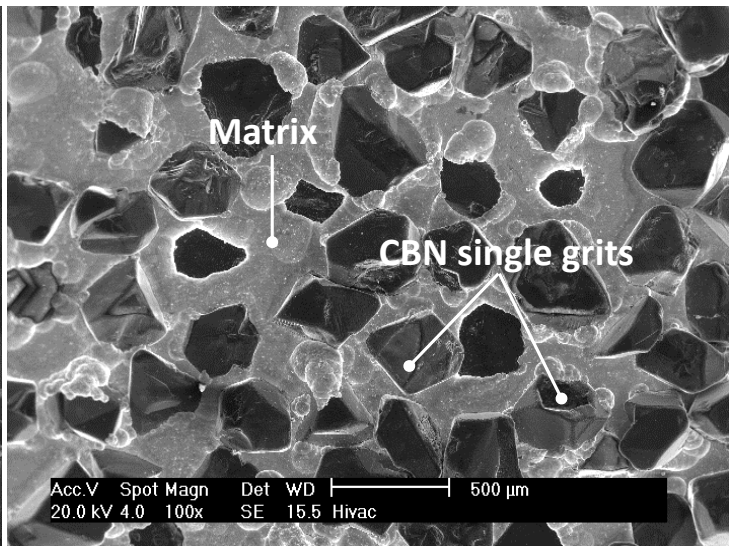

b)

Fig. 3: ESEM images of electroplated abrasive pads: a) diamond and b) CBN abrasives. 


\subsection{Manufacture of the micro-abrasive arrays and wear/cutting test set up}

A laser (DMG LASERTEC 60 HSC Q-switched Nd: YAG; wavelength, $1064 \mathrm{~nm}$ ) has been used for the manufacture of the PCD/PCBN arrays. Sets of pre-optimised laser parameters have been used to minimize the thermal affected zone in the manufacture of micro-edges; for PCD (pulse duration $\tau$ [10 $\mu \mathrm{s}$ ], average laser power $\mathrm{P}_{\mathrm{m}}$ [70 W], laser frequency $f[30 \mathrm{kHz}]$, feed speed $\left.v\left[400 \mathrm{~mm} \mathrm{~s}^{-1}\right]\right)$ and for PCBN $\left(\tau[10 \mu \mathrm{s}], \mathrm{P}_{\mathrm{m}}[70 \mathrm{~W}], \mathrm{f}\right.$ [20 kHz], $v$ [300 $\left.\mathrm{mm} \mathrm{s}^{-1}\right]$ ). The cutting edges of the micro-arrays (Fig. 4b) have been generated with the same average values for both PCD and PCBN materials: rake angle $6^{\circ}$ and clearance angle $30^{\circ}$; this geometry has been selected in order that the acute cutting edge angle which results will facilitate analysis of the progression of wear as a function of the microstructural features of the composites.

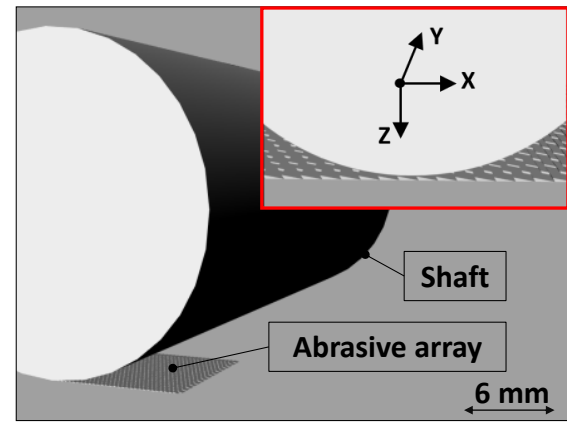

a)

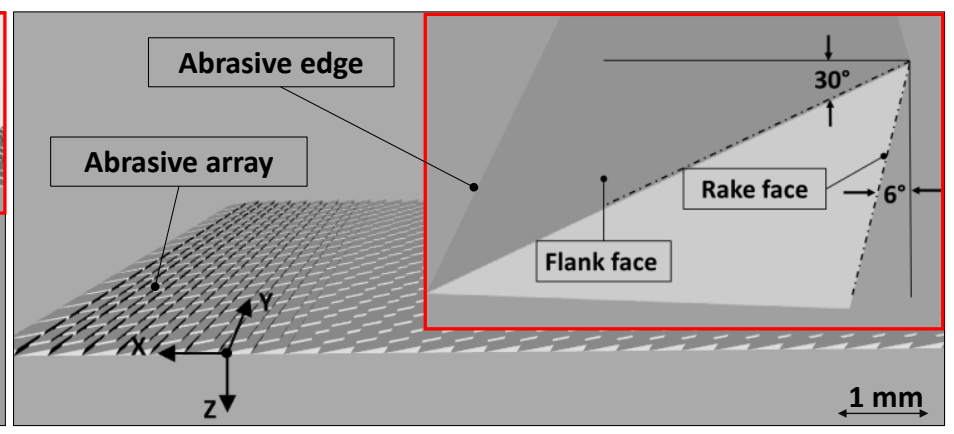

b)

Fig. 4: Schematic of the test setup: a) full shaft diameter in contact with the abrasive array and detail of the cross section of the contact array/shaft; b) 3D enlarged view of the array and detail of a single micro-abrasive edge for the laser tool path. 
A 5-axis machining centre (Makino A55; max. spindle speed 19,000 rpm; spindle power $30 \mathrm{~kW}$ ) was used for the wear/cutting tests and the cutting forces were acquired at a sampling rate of $10 \mathrm{kHz}$ (see setup Fig. 5). A dedicated fixturing system was employed to accommodate a 3-axis miniature dynamometer (Kistler 9317b) connected to three (one for each axis) charge amplifiers (Kistler 5011B10) and then to a data acquisition board (National Instrument BNC-2110) and dedicated Labview application to save and process the signals (Fig. 5).

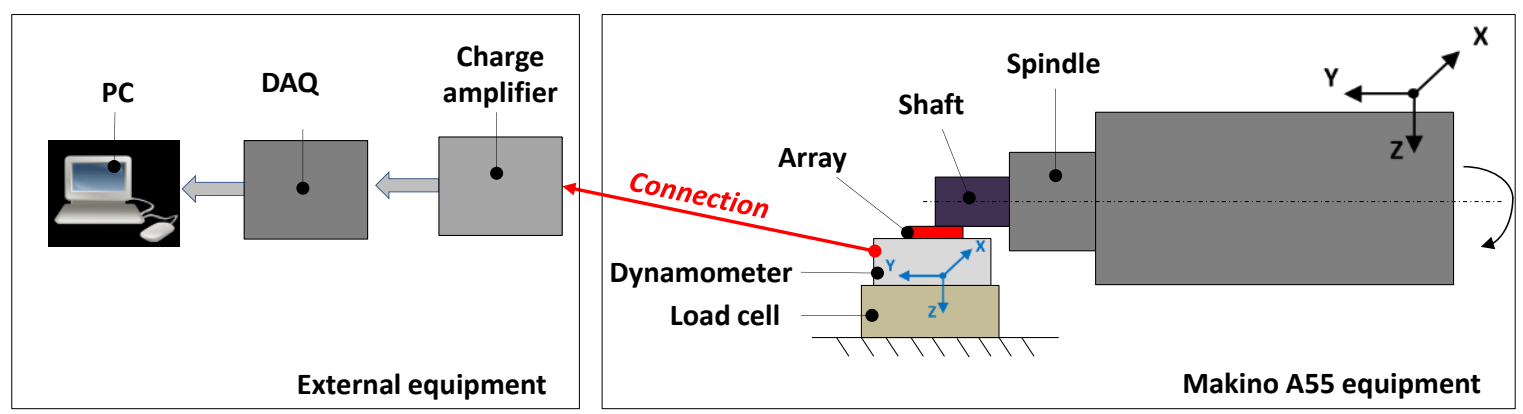

Fig. 5: Schematic of the monitoring equipment diagram for the acquisition of the forces.

With the workpiece $\left(\mathrm{SiO}_{2}\right.$ shaft $)$ being rotated the manufactured micro-arrays /electroplated pads performed translational motion in along x-axis (Fig. 4). The depth of cut (in the z-axis) was initially chosen $5 \%$ (i.e. $5 \mu \mathrm{m}$ per pass) of the total height of the designed micro-cutting edges; the subsequent trials demonstrated this value to be suitable for PCD arrays since the wear progression was low enough to be characterised. However, for PCBN this depth of cut value $(5 \mu \mathrm{m})$ resulted in rapid wear of the microedges, which did not facilitate a detailed understanding of the various stages in the wear process; accordingly, a depth of cut of $1 \mu \mathrm{m}$ per pass was selected for PCBN arrays 
/electroplated CBN abrasives. The wear/cutting tests for the abrasive elements consisted of repeated sets of 250 passes (length of cut, $2.5 \mathrm{~m}$ ), measurement of forces and wear, progressing to a total of 5000 passes (length of cut, $50 \mathrm{~m}$ ) for the PCD arrays /electroplated diamond abrasives, and to a total of 1000 passes (length of cut, $10 \mathrm{~m}$ ) for the PCBN arrays/electroplated CBN. Each pass consisted of a combination of the following motions: touch between abrasive element and rotating shaft to reference the system; exit from contact and adjust relative position in z-axis to the required depth of cut; translational motion of the array ( $\mathrm{X}$ direction) covering the length of the array (10 $\mathrm{mm}$ ), shaft lift off (-Z direction); final translational of the array (-X direction) for cutting action. Throughout the wear/cutting trials, a coolant (Houghton 3380, concentration 8$10 \%$ ) was delivered through the nozzle (100 $\mathrm{mm}$ above the abrasive array) at a pressure of 20 bar. To evaluate the wear progression/performance of the arrays, scanning electron microscopy (SEM Philips XL30) has been conducted after each intermediate set of passes.

\section{RESULTS AND DISCUSSIONS}

\subsection{Geometrical analysis of the PCD ordered arrays and electroplated diamond} abrasive pads in their fresh state

Previous work on diamond abrasive arrays [7] has focussed on the production of staggered pattern of cutting elements, but the sharpness of the manufactured abrasive edges together with the positive rake angle (Fig. 4b) represent a novelty of the work presented here. It is known that negative rake angles give stronger cutting/abrasive 
edges (less tendency for fracture) but positive rake angles decrease both the cutting forces and the vibration occurring during cutting while facilitating efficient chip flow [35].

The ESEM micrographs of the PCD array in the as-manufactured state (i.e. before any micro-cutting/wear tests) in Fig. 6 show the regular pattern of similar shaped diamond abrasive elements processed surface of the CMX850 fine grained (15 vol\% Co) PCD composite; the staggered arrangement of cutting elements are designed to provide preferential paths for chip flow.

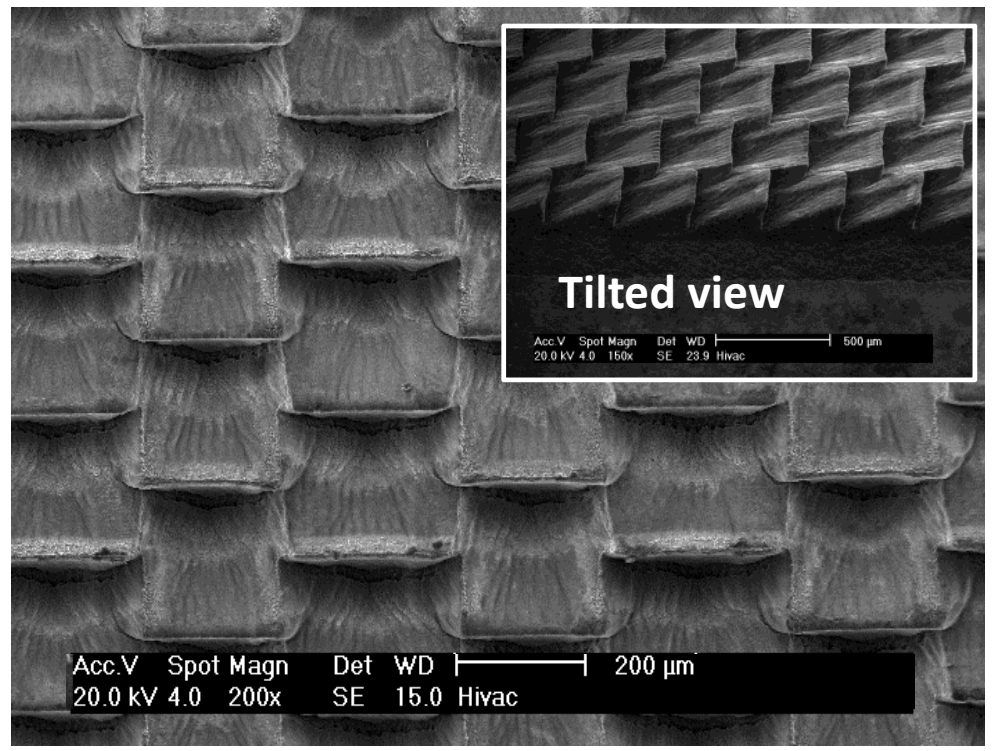

Fig. 6: SEM micrograph of a PCD CMX850 micro-array manufactured with PLA in top view; insert - tilted view.

As can be observed in the higher magnification images presented in Fig. 7, the PCD micro-abrasive edge geometry consists of a sharp edge with an average rake angle of $6^{\circ}$ to a depth of $100 \mu \mathrm{m}$. 


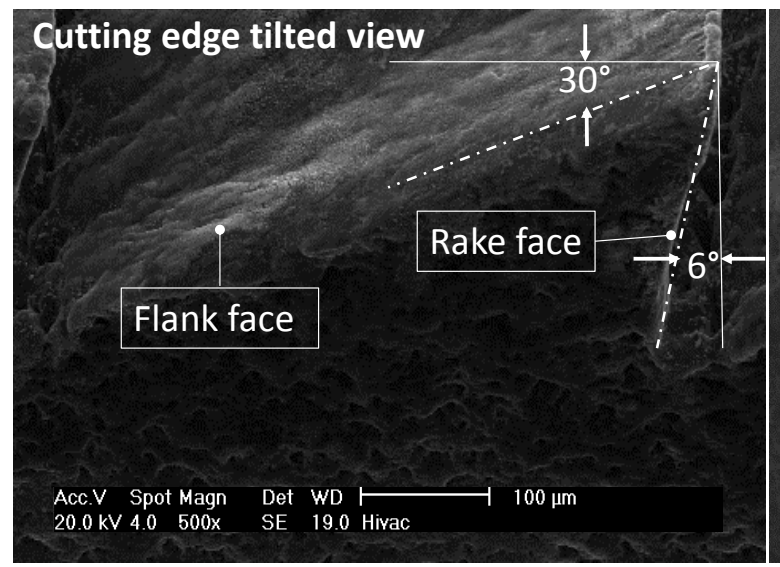

a)

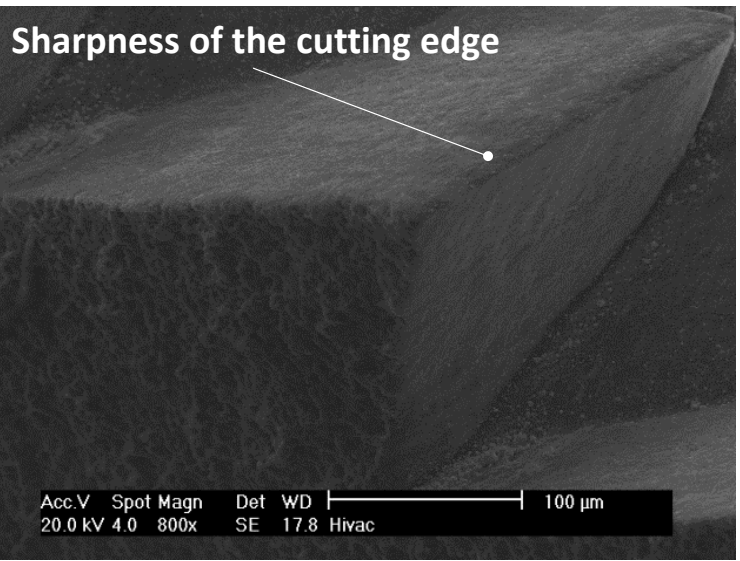

b)

Fig. 7: SEM images of the CMX850 fine grained micro-array showing the abrasive element geometry: a) side view; b) tilted view.

As mentioned, in order to benchmark the performances of the novel orderly abrasive arrays, two types of electroplated abrasive elements have been selected for a comparative test; an example of the cross section and top view of the CBN electroplated specimen is presented in Fig. 8.

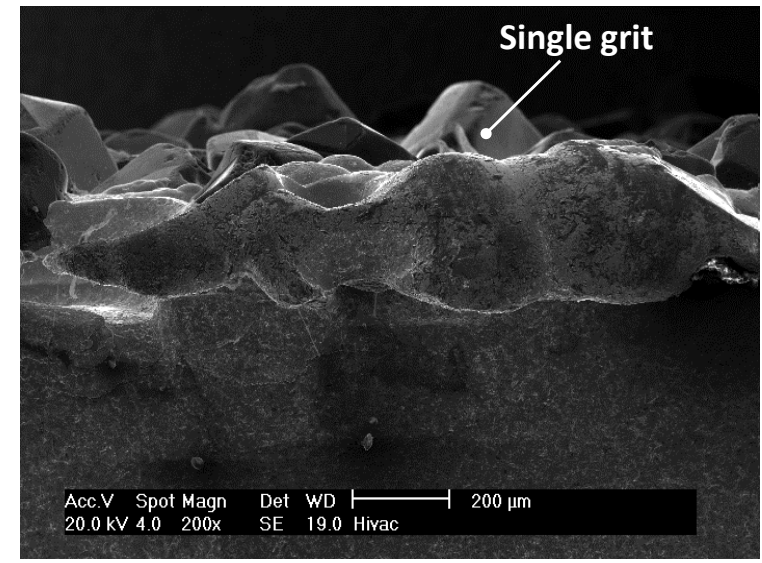

a)

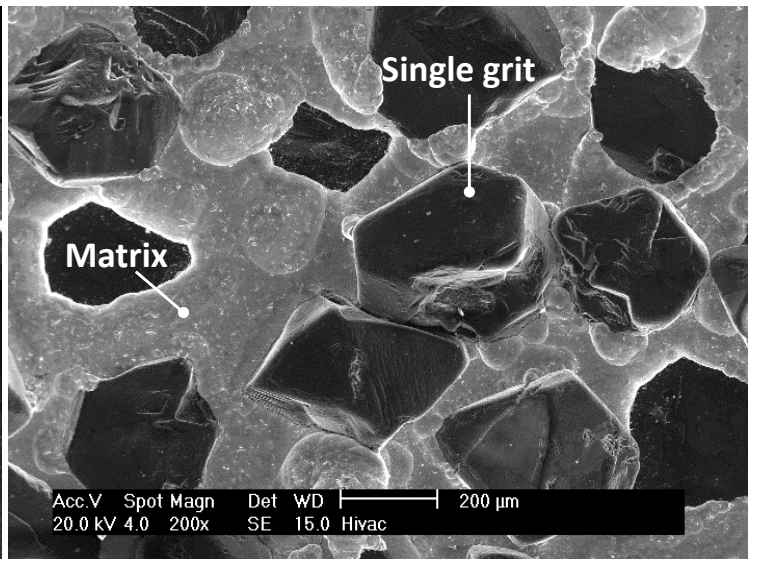

b) 
Fig. 8: SEM of a representative electroplated CBN abrasive material in a) side view and

$$
\text { b) top view. }
$$

Fig. 9 depicts an example of a typical grit of the electroplated abrasive specimens; the roundness/bluntness of the edges of the individual abrasive grains can be seen (particularly when contrasted with the sharpness of the micro-abrasive edges presented in Fig. 7); this difference in sharpness not only has implications on the chip formation but also on the contact area between the single grit/edge and the workpiece (i.e. smaller values for orderly arrays), with further effects on the values of the specific contact/cutting loads.

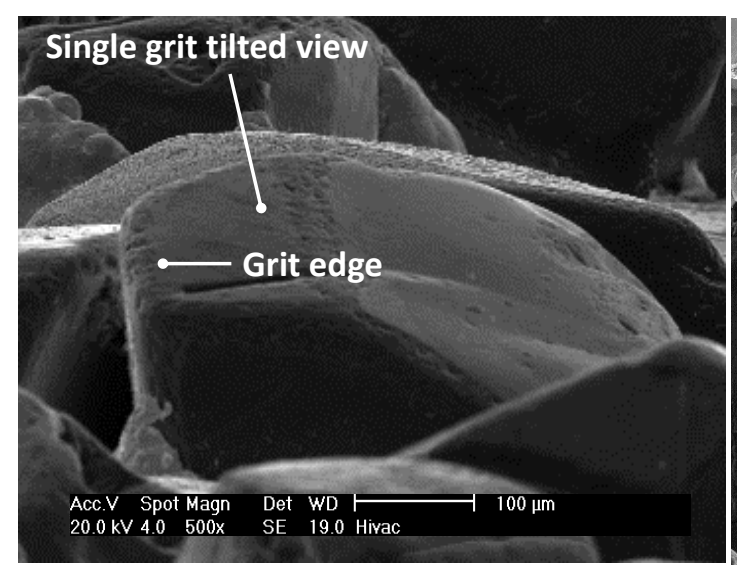

a)

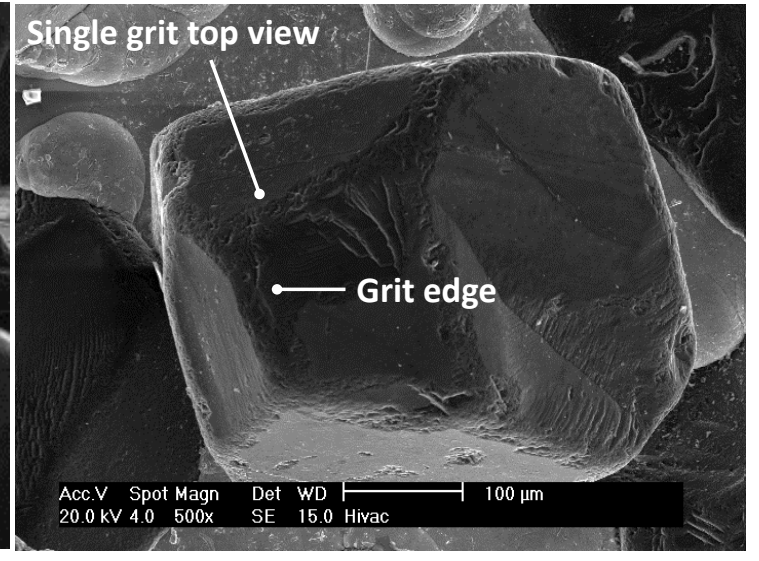

b)

Fig. 9: SEM imaging of a single CNB grit in an electroplated PCBN abrasive pad: a) tilted and b) top views.

\subsection{Wear/failure evaluation of PCD abrasive arrays against electroplated diamond via a micro wear/cutting test}

As well as the direct mechanical loads, fracture (being the typical failure mechanism for brittle materials) could be caused by thermal shock thus resulting in the occurrence of a 
thermal-related wear/damage [30]. As a consequence of the increased number of passes, it has been found that the prevalent wear of the CMX850 fine grained diamond arrays is that of slice fracture (Fig. a). This is because CMX850 abrasive arrays tested in this work display a wear progression which starts with a micro-damage (chipping) of the single abrasive edge followed by a consequent macro-damage (slice fracture) with the increasing number of passes leading to elevated loads at the micro-edge/grit contact with the workpiece. Slower wear progression of the CTM302 mixed grain diamond abrasive array is shown in Fig. b.

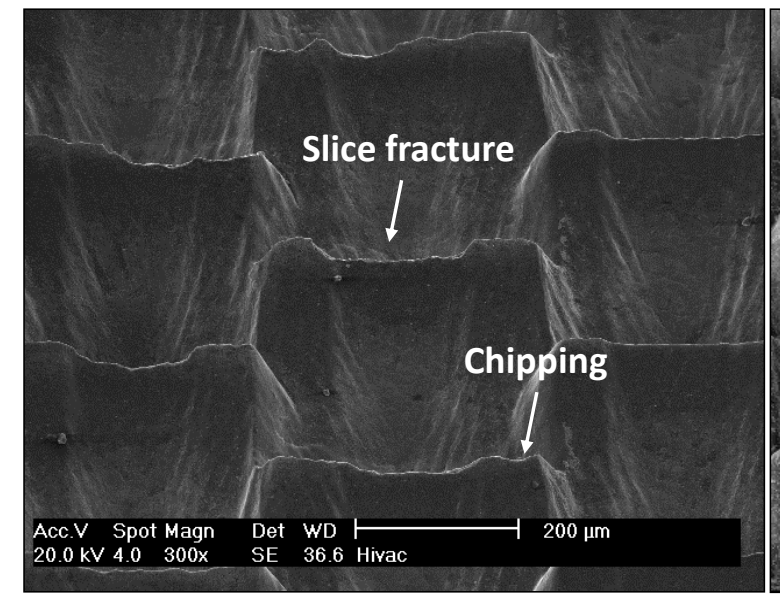

a)

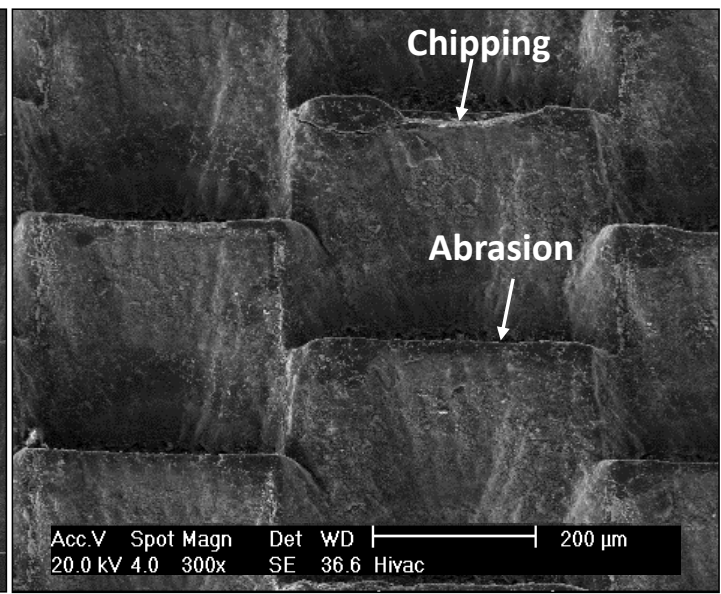

b)

Fig. 10: ESEM of wear features for abrasive micro-arrays after 5000 passes ( $5 \mu \mathrm{m}$ depth of cut): a) CMX850 fine grained diamond; b) CTM302 mixed grained diamond.

The different wear progression are possibly related to the different cobalt binder percentage and the diamond particle size and this can be explained by using the physical principle of volumetric strain produced in a material as a consequence of the change in temperature [36]; Eq. 1 was used in a previous work to study the dependence of the volumetric strain from the change in temperature occurring during the synthesis of PCD 
composite [37], [38] and for this work it has been rearranged in term of the change in temperature occurring in the abrasive edge during the wear test for every interrupted number of passes:

$$
e=\alpha * V_{0} *\left(T_{a m b}-T_{\text {process }}\right)
$$

where $\mathrm{e}$ is the volumetric strain in the material $\left[\mathrm{m}^{3}\right], \alpha$ the thermal expansion coefficient $\left[K^{-1}\right], V_{0}$ the volume prior deformation $\left[m^{3}\right], T_{a m b}-T_{\text {process }}[K]$ the change in temperature occurring during the test. The mismatch (circa $80 \%$ ) of thermal expansion coefficient $\left.\alpha_{P C D}\left(2.5 \times 10^{-6} K^{-1}\right)<\alpha_{C o}\left(13 \times 10^{-6} K^{-1}\right)\right]$ [37] could lead to high compressive stress in the diamond grains and low tensile stress in the Co binder, causing internal residual stresses at the interface $\mathrm{PCD} / \mathrm{Co}$, leading to polycrystalline composites fracture. This phenomenon is likely to occur in the fine grained diamond composites caused by higher Co percentage and the smaller PCD grains, so more expansion of Co and compression of PCD could result in an increase of residual stresses and a consequent reduced wear resistance; the increased amount of metallic phase in the fine grained PCD could also lead to a decreased thermal resistance [33]. These possible findings on the influence of material thermal properties versus wear characteristics are in agreement with literature: a study in 1996 has shown that the fine grain PCD diamond has higher compressive stress when compared to the mixed grained diamond; furthermore, higher amounts of metallic phase is responsible for greater amount of extrusions and reduced thermal resistance [33].

As described in paragraph 2.2 , the performed test combined cutting and sliding leading to a type of wear which could be generically identified as abrasive [39]. A classification 
reported in the literature [39] defined single-cycle deformation mechanisms as those that occur for distortion, displacement and fracture of the material; while repeatedcycle damage mechanisms as those requiring repeated contact for distortion and fracture to occur, such as in fatigue and delamination phenomena. When the hardness of abrasive is higher than the machined material, a single-cycle deformation mechanism is expected [39], though the results show that a repeated-cycle damage mechanisms is necessary for the fracture to be manifested: the damage in the CTM302 mixed grained diamond becomes visible only after multiple cycles (5000 passes corresponding to a length of cut of $50 \mathrm{~m}$ ) proving that repeated loading might be the cause of the coalescence and propagation of cracks. The electroplated diamond abrasive pad containing D501 sized abrasives has shown mainly micro-damaged grits with consequent flattening of $25-35 \%$ of the grits initial height (Fig. 11b) from the beginning of the test (Fig. 11a), with a type of abrasive wear similar to the mix grained diamond. It must be noticed that the grits considered in Figs. 11a-b are relative to the same grit which has been observed before and after test. The wear occurring in the CTM302 mixed grain PCD array and in the electroplated diamond abrasive pads is a mild abrasive wear [39]. A possible explanation of such behaviour could be that the stress is constantly maintained below the elastic limit of the material, causing the repeated-cycle damage mechanism to dominate [6]. 


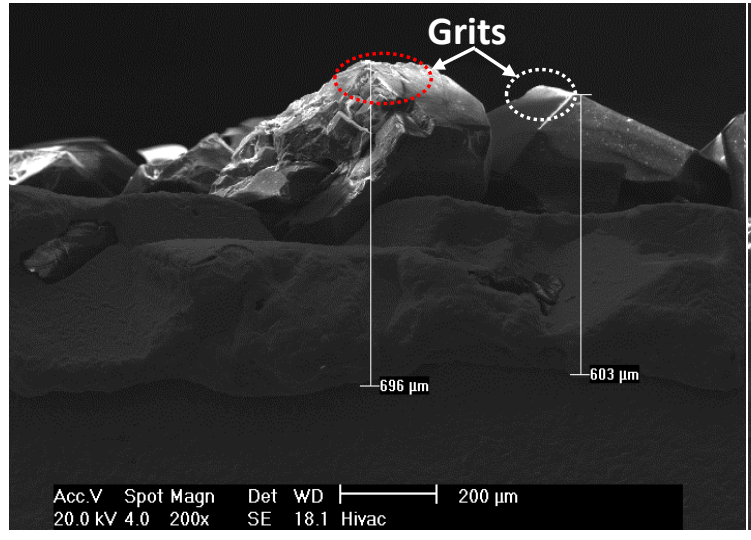

a)

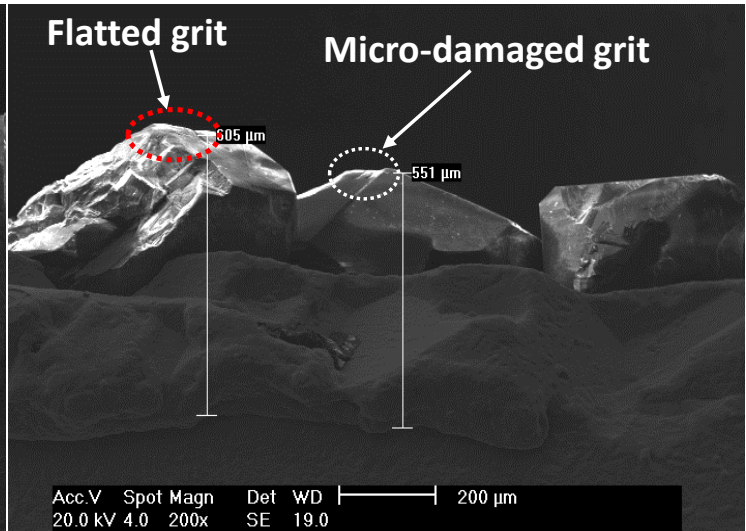

b)

Fig. 11: ESEM micrographs demonstrating the reduction in height (i.e. flattening) of electroplated diamond grits: a) in "fresh" condition b) after 5000 passes (for $5 \mu \mathrm{m}$ depth

$$
\text { of cut). }
$$

ESEM for the CMX850 fine grained diamond array (Fig. 12a) has shown that fracture of the micro-abrasive edge occurred already after $30 \mathrm{~m}$ length of cut (compared to $40 \mathrm{~m}$ for the mixed grained); having smaller diamond particles (and consequently higher binder concentration) could cause an increased tensile cobalt stress and consequently an higher compressive stress on the diamond grains [6], [33]. Thus, in the fine grain diamond (CMX850) the effect of the residual stresses on the wear performances is higher than in CTM302, and this could lead to quicker edge wear (as shown by SEM analyses reported on Figs. 12a-b). 


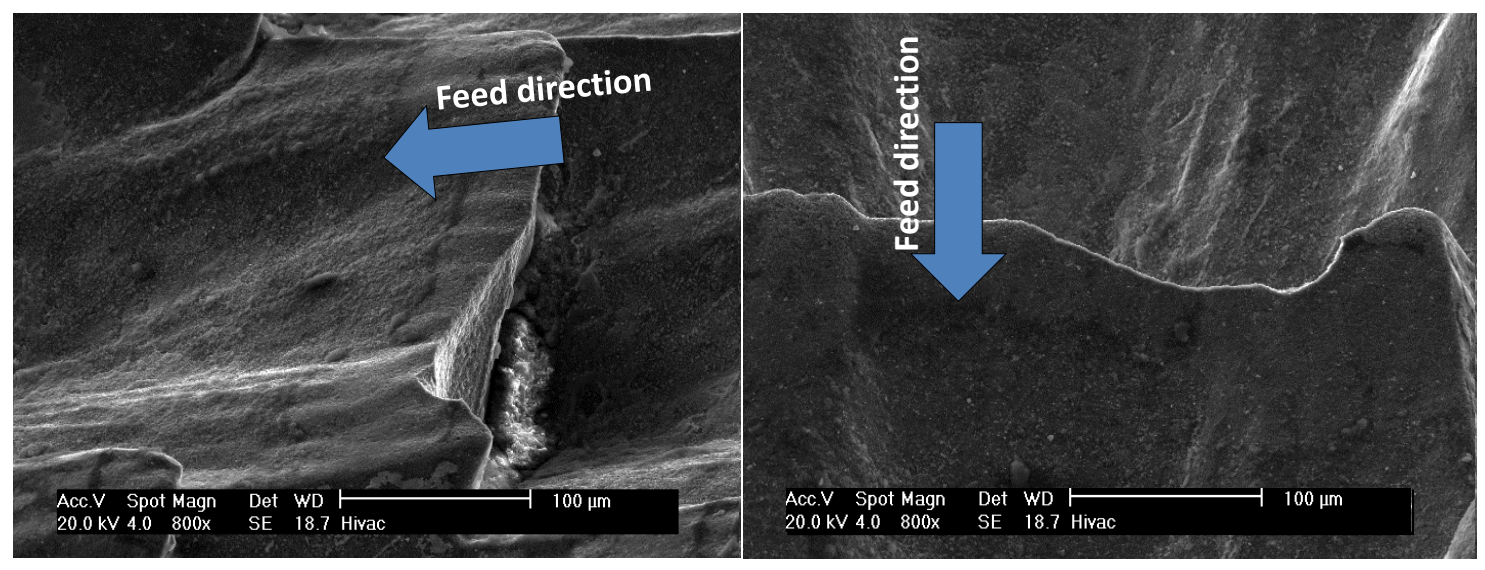

a)

b)

Fig. 12: ESEM images proving the fracture of CMX850 fine grained PCD array after 3000 passes ( $5 \mu \mathrm{m}$ depth of cut): a) side view, and b) front view of a micro-abrasive edge. The CTM302 mixed grained PCD showed a different type of behaviour when compared to the fine grained material: Fig. 13 represents an example of micro-edge after 3000 passes, proving that no crack or chipping is present at this stage of the test; this could be due to the larger diamond grain size and the reduction of metal binder presence, thus less compressive stresses generated in the matrix resulting in material slower wear [6]. 


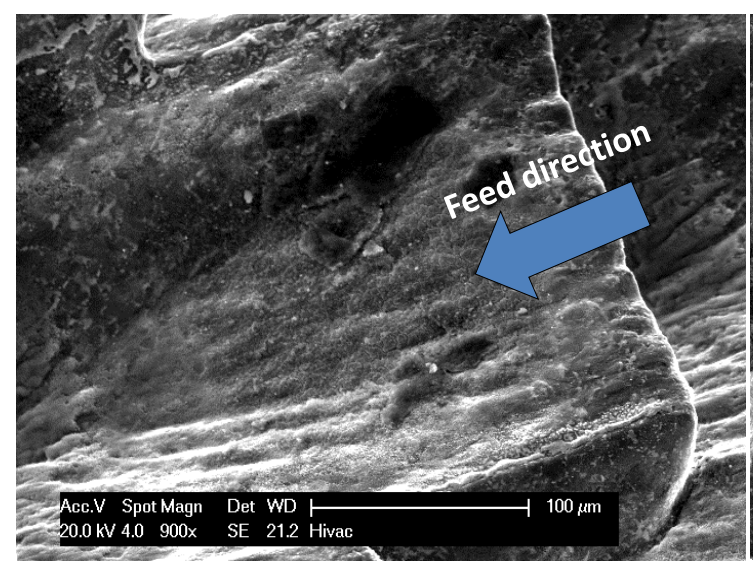

a)

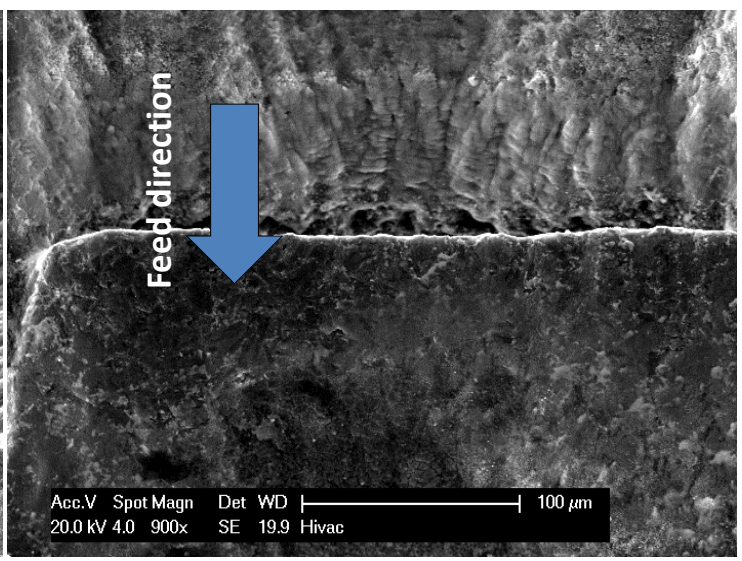

b)

Fig. 13: ESEM images after 3000 passes ( $5 \mu \mathrm{m}$ depth of cut) in CTM302 mixed grained PCD array: a) tilted view of the worn micro-abrasive edge, b) front view of the microabrasive edge.

Although prevalent wear progression for the CTM302 mixed grained array seems to be of abrasive type, a first appearance of cracking occurred in this composite only at the grain/binder boundary of one micro-edge (Fig. 14a) after 4000 passes: here the maximum contact pressure/load with the workpiece has been measured. After the maximum contact pressure has been achieved at 4000 passes (contact pressured have been calculated based on the acquisition of the cutting force as shown in the test set-up in Fig. 5), the repeated cycle deformation mechanism on the single abrasive edge (between 4000 and 5000 passes) caused the formed crack to break and the result of this is shown in Fig. b, where the abrasive edge at the end of the 5000 passes is depicted. In the testing interval of 4000 to 5000 passes a decrease of contact load has been recorded, indicating that the cracking of the abrasive edge occurred in that interval. The bigger grain dimension (90\%) and the decrease of binder percentage $(5 \%)$ in the mixed 
grained in respect to the fine grained structure, are the main causes of the slower wear progression of the CTM302 mix grained array: the compressive stresses in the diamond grains could be smaller and cause lower residual stresses in the matrix if compared to the CMX850 fine grained material; this result confirms what has been previously demonstrated in literature [37].

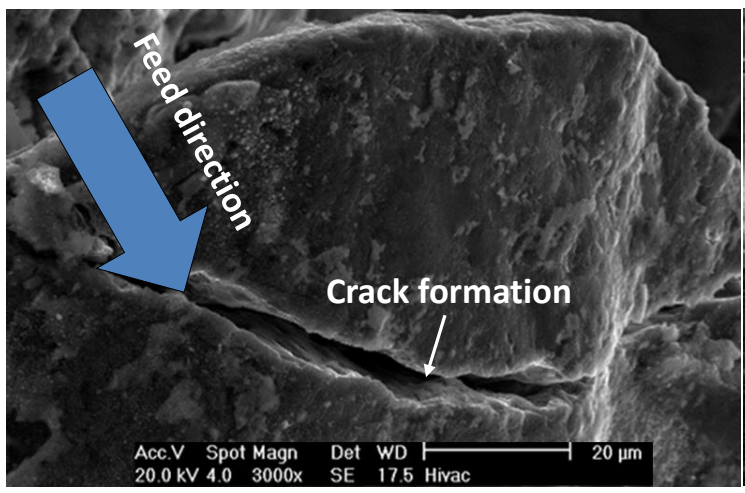

a)

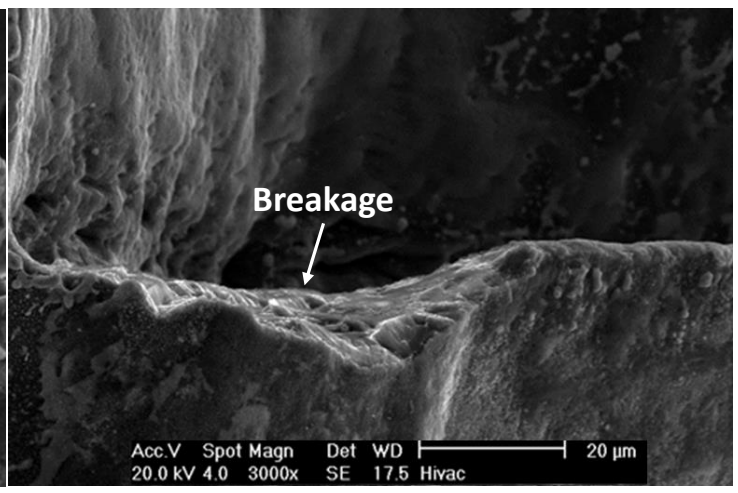

b)

Fig. 14: ESEM images of wear behaviour of the CTM302 micro-abrasive edge: a) after 4000 passes, b) after 5000 passes ( $5 \mu \mathrm{m}$ depth of cut).

The signal forces acquired during the wear/cutting test have shown randomly variable signal peaks in time domain in the electroplated diamond pads (Fig. 15b) and homogeneous signal peaks in the abrasive arrays (Fig. 15a). This is mainly due to the lower density and randomness of the grits in the electroplated pads and to the different number of micro-edges/grits instantaneously in contact with the $\mathrm{SiO}_{2}$ shaft during the testing of the different specimens (many edges, few grits in the same contact area). 


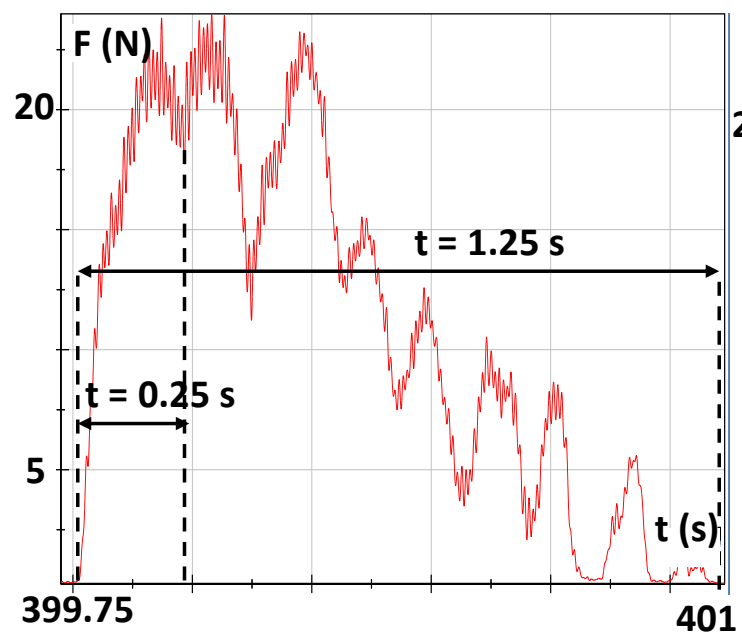

a)

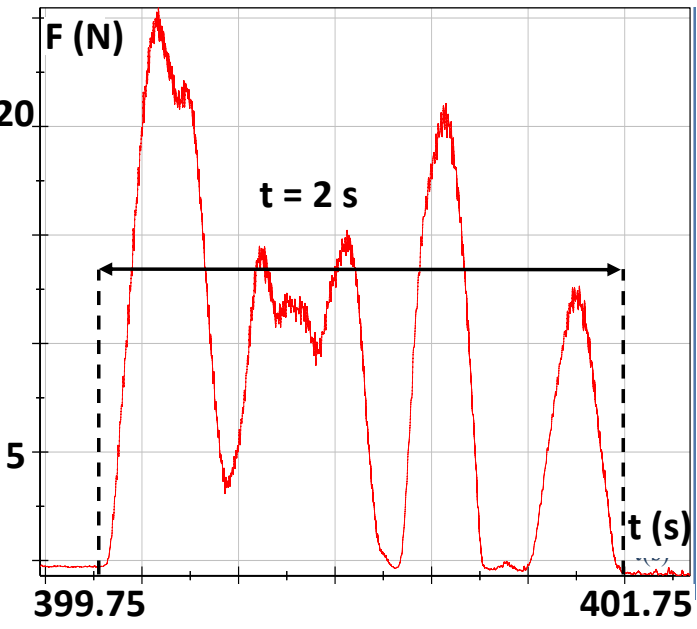

b)

Fig. 15: Graph showing a typical signal acquired in a single pass with the corresponding time of contact of the shaft upon: a) the CMX850 fine grained array; b) the D501 electroplated diamond abrasive.

Fig. 16 is representative of the different densities in the case of the micro-edges per array (Fig. 16a) and in the case of the grits per electroplated area (Fig. 16b).

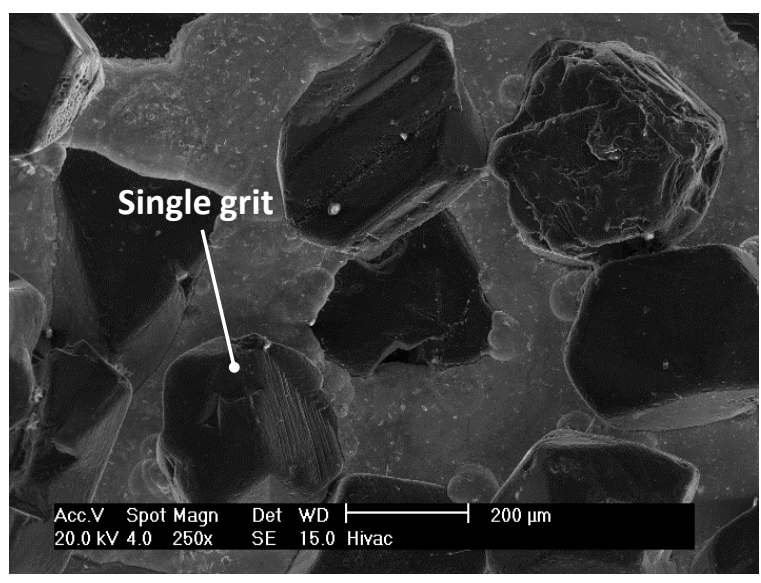

a)

b)

Fig. 16: ESEM example of the variation in edges/grit density per same surface area: a) 12 micro-edges in the case of the array, b) 7 grits in the case of the electroplated specimen. 
The direct consequence of the difference in density is the cutting force signal acquired during the test. Fig. 15a shows an example of the signal acquired during a single pass in the CMX850 fine grained array and Fig. 15b the one related to the electroplated diamond pad.

The large peaks ( $t=0.25 \mathrm{~s}$ ) of the force diagrams (Fig. 15a) are associated with groups of micro-edges/grits corresponding to the contact between the array/electroplated abrasives with the shaft during the roto-translational motion and the $\mathrm{X}$ axis represents the time domain (with notations for a single pass). As shown in Fig. 17, the calculated overall time necessary for the shaft to cover the length of an array/electroplated abrasives (under test condition reported in paragraph 2.2 ) in a single pass is $2 \mathrm{~s}$, which in the case of D501 electroplated specimen, corresponds to the experimental time (2 s), where this is defined as the time interval spent to complete a single pass (Fig. 15b). The abrasive arrays have shown a gap between the calculated time and the experimental time spent in each pass during testing: the time axis in Fig. 15a shows that $1.25 \mathrm{~s}$ is the time interval spent from the array to complete a single pass. The difference in time spent for each pass and the variation of signal acquired are possibly due to the following reasons: (i) workpiece diameter reduction: the entire depth of cut has been done by the front cutting edges, thus more material is removed from the shaft with the use of the abrasive arrays reducing the contact time in a single pass (from $2 \mathrm{~s}$ to $1.25 \mathrm{~s}$ ) and provoking only the left side of the array to wear out (Figs. 17-18a); (ii) edges height homogeneity: the random height typical of the electroplated pad does not guarantee constant contact with the shaft producing variable force peaks (Fig. 15b). 


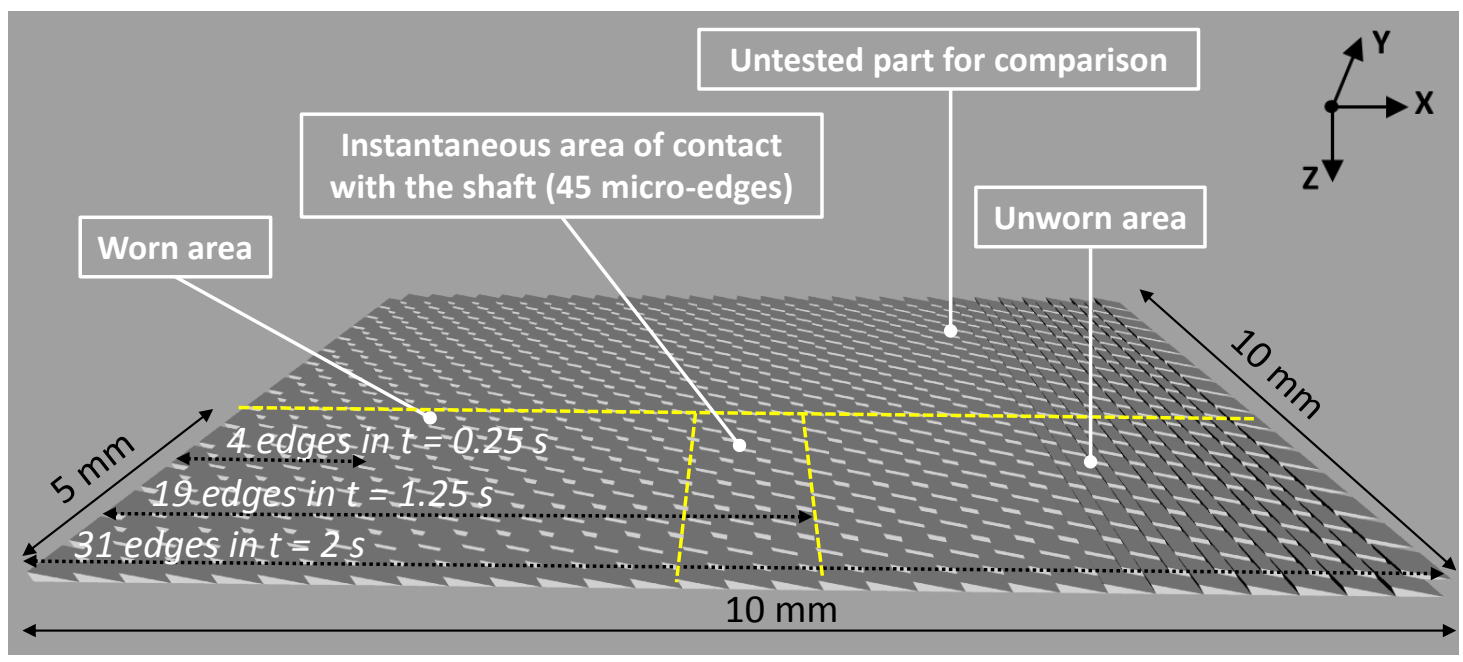

Fig. 17: CAD schematic of the manufactured array with dimensions, number of microedges in instantaneous contact with the shaft, tested area, untested area, worn and

$$
\text { unworn areas. }
$$

As a result of this, in the case of the PCD abrasive arrays, only part of the specimen has been subjected to wear (Fig. 18a). The trailing side (Fig. 17) remained unworn (Fig. 18b) because it has not been in "active" cutting/contact with the shaft.

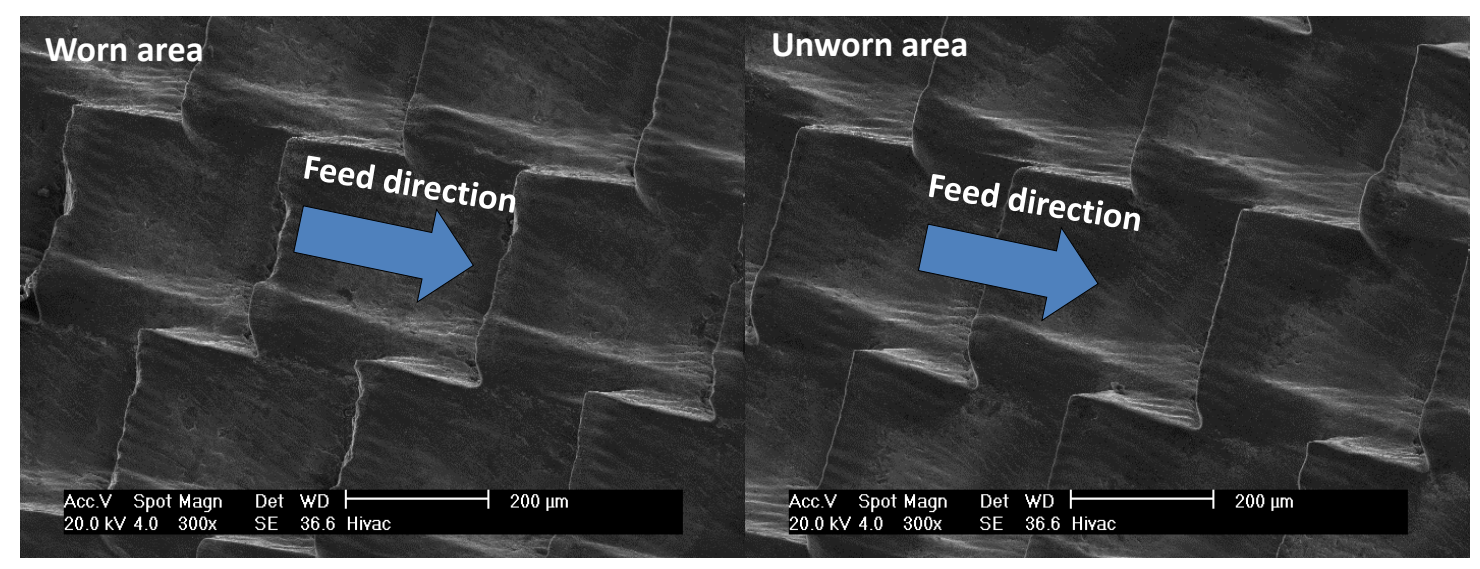

a)

b)

Fig. 18: ESEM images of different abrasive edges positioning in the same CMX850 array after 5000 passes: a) most worn surface corresponding to highest contact pressure with 
the shaft $(t<1.25 \mathrm{~s})$; b) unworn surface corresponding to time interval of not acquired contact loads ( $\mathrm{t}>1.25 \mathrm{~s})$.

To calculate and compare the contact loads for the PCD abrasive array and the electroplated diamond pads, two main considerations are necessary: (i) the surface density of the orderly micro-abrasive edges (for orderly arrays) and the abrasive grits (for electroplated elements) are significantly different; approx. ratio of 10:4 per $\mathrm{mm}^{2}$ for the orderly micro-arrays and for this reason, the measured forces during the wear test are not directly comparable; (ii) there is a geometrical variability of the grits (e.g. height, shape) for the electroplated pads when compared to the repeatable micro-abrasive edges.

To enable the evaluation of the specific contact loads between the abrasive arrays/electroplated diamond grit and the $\mathrm{SiO}_{2}$ shaft, their area of contact needs to be evaluated prior to and at different time intervals of the cutting/wear test programme. Topological scans (using Talysurf CLI 1000) of the orderly arrays (Fig. 19) and electroplated (Fig. 20) pads have been carried out to achieve the evaluation of the contact surface of representative micro-abrasive edges/grits with the $\mathrm{SiO}_{2}$ counterpart. An example of a micro-edge at the initial stage of the test (Fig. 19a) and its contact area (blue area in Fig. 19b) with the rotating shaft is presented. The contact area has been measured by considering a cross section on the cutting edge at a distance measured from its top corner equal to the depth of cut (in this case $5 \mu \mathrm{m}$ ); this corresponds to the area of contact of a single abrasive edge with the rotating shaft. Thus, for the cutting edge after 200 passes the contact measured area (Fig. 19b) for $5 \mu \mathrm{m}$ depth of cut is 
$10.6 \%$ of the total area scanned area (Fig. 19a). Similarly, the blue area in Fig. 19d represents the measured area of contact for a micro-edge at the end of the test (after 5000 passes), which measures $25.8 \%$ of the total scanned area (for $5 \mu \mathrm{m}$ depth of cut).

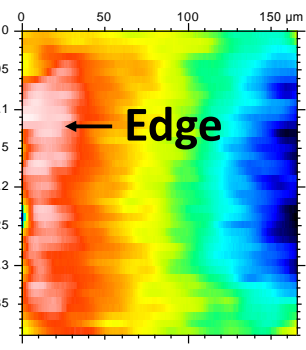

a)

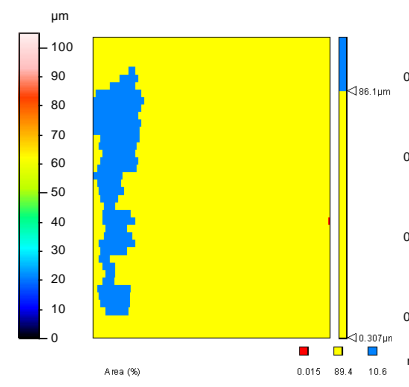

b)

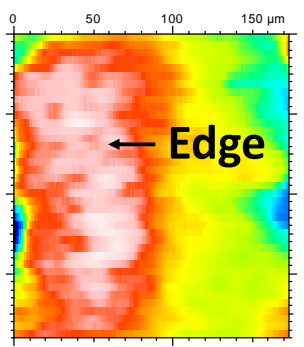

c)

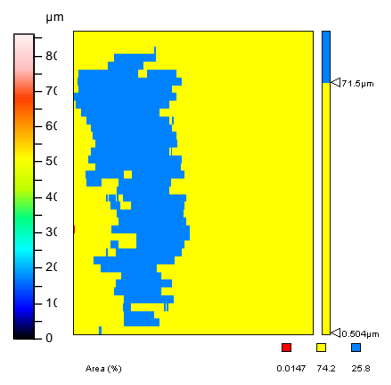

d)

Fig. 19: Example of the abrasive/cutting elements in a micro-array and their area of contact with the shaft during test: a) topographical measurement of a single abrasive element at a first stage of the test (250 passes); b) measured area of contact of the single abrasive element via thresholding process after 250 passes; c) topographical measurement of a single abrasive element after the test (5000 passes); d) measured area of contact of a single abrasive element via thresholding process after the test $(5000$ passes).

The same procedure has been used to evaluate the contact areas of an average grit size of the electroplated abrasive pads with the shaft at different stages of the test: Fig. 20a represents the topographical profile of a single grit after 250 passes while the blue area in Fig. 20b depicts the measured contact area between grit and shaft; similarly, Fig. 20c indicates a worn grit after 5000 passes, whose contact area is represented in Fig. $20 \mathrm{~d}$. 


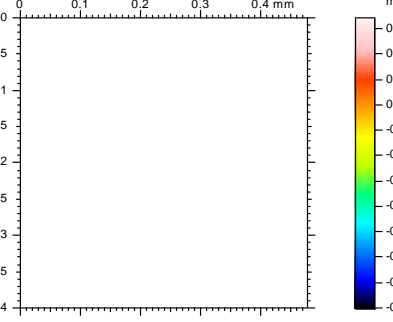

a)

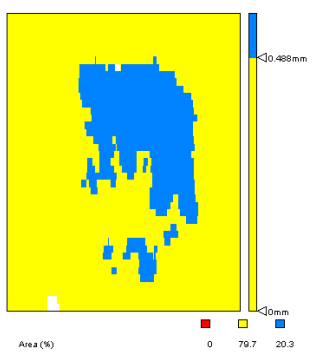

b)

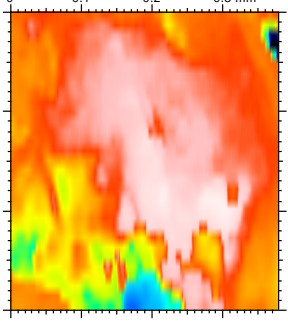

c)

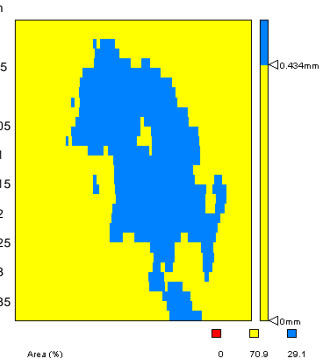

d)

Fig. 20: Example of a single grit of an diamond electroplated pad and its area of contact with the shaft during test: a) topographical measurement of a single grit in the first stage of the test (250 passes); b) measured area of contact of the single grit with the shaft via thresholding process (after 250 passes); c) topographical measurement of a single grit after the test (5000 passes); d) measured area of contact of a single grit via thresholding process after the test (5000 passes).

The contact pressure (see Eq. 2) between a single grit/edge and shaft has been calculated taking into account the number of micro-edges/grits present in the instantaneous contact area of $5 \mathrm{~mm}^{2}$ (Fig. 17). In particular, after a statistical evaluation of the protrusion height of the grits and their number contacting the shaft, it has been considered 45 micro-edges (Fig. 17) versus a number of 7 grits in the instantaneous contact area for orderly micro-arrays and electroplated diamond abrasive pads.

$$
p=\frac{F}{N * A}
$$

Where $A$ is the area of contact between a single abrasive edge/grit with the shaft, $\mathrm{N}$ is the number of abrasive edges/grits in the instantaneous contact area of $5 \mathrm{~mm}^{2} ; F$ is the average acquired contact force (in Z-axis); $p$ is the contact pressure of the shaft on the 
single abrasive edge/grit. Table 2 contains all of the measured values for $A$ and the calculated value for $\mathrm{p}$ after 250 passes and after 5000 passes.

Table 2: Measured values of contact area of the micro-edge/grits and the calculated initial and final contact pressures.

\begin{tabular}{lllll}
\hline Specimen & $A_{250}\left[\mathrm{~mm}^{2}\right]$ & $A_{5000}\left[\mathrm{~mm}^{2}\right]$ & $p_{250}\left[\mathrm{~N}^{*} \mathrm{~mm}^{-2}\right]$ & $p_{5000}\left[\mathrm{~N}^{*} \mathrm{~mm}^{-2}\right]$ \\
\hline PCD CTM302 & 0.012 & 0.061 & 26.9 & 5.33 \\
PCD CMX850 & 0.012 & 0.061 & 29.3 & 8.60 \\
Electroplated D501 & 0.003 & 0.018 & 336 & 135 \\
\hline
\end{tabular}

The wear progression of the micro-arrays manufactured on different PCD composites as well as of electroplated pads have been examined: the slower wear and better wear resistance achieved in the CTM302 mix grained array has been analysed microscopically and also been confirmed from the calculated contact pressure per abrasive edge.

The calculated contact pressures are shown in Fig. 21 (with a Y axis in logarithmic scale) as a function of the length of cut, the general wear performances are depicted for all of the three specimens: both PCD micro-cutting arrays (CTM302 and CMX850) have proved their superior wear-resistant properties when compared to a benchmarked electroplated diamond pads (D501). Despite the fact that a positive rake angle leads to a weaker cutting edge and an increases tendency for edge breakage [35], these results demonstrate that the orderly micro-cutting edge arrays produced $70 \%$ lower contact pressures in comparison with the negative rake angle typical of the grits in the electroplated specimens. This being corroborated with the better wear performance, represents a step change in replacing electroplated pads (with stochastically distributed abrasives) with arrays of micro-cutting edges for grinding/polishing operations. 


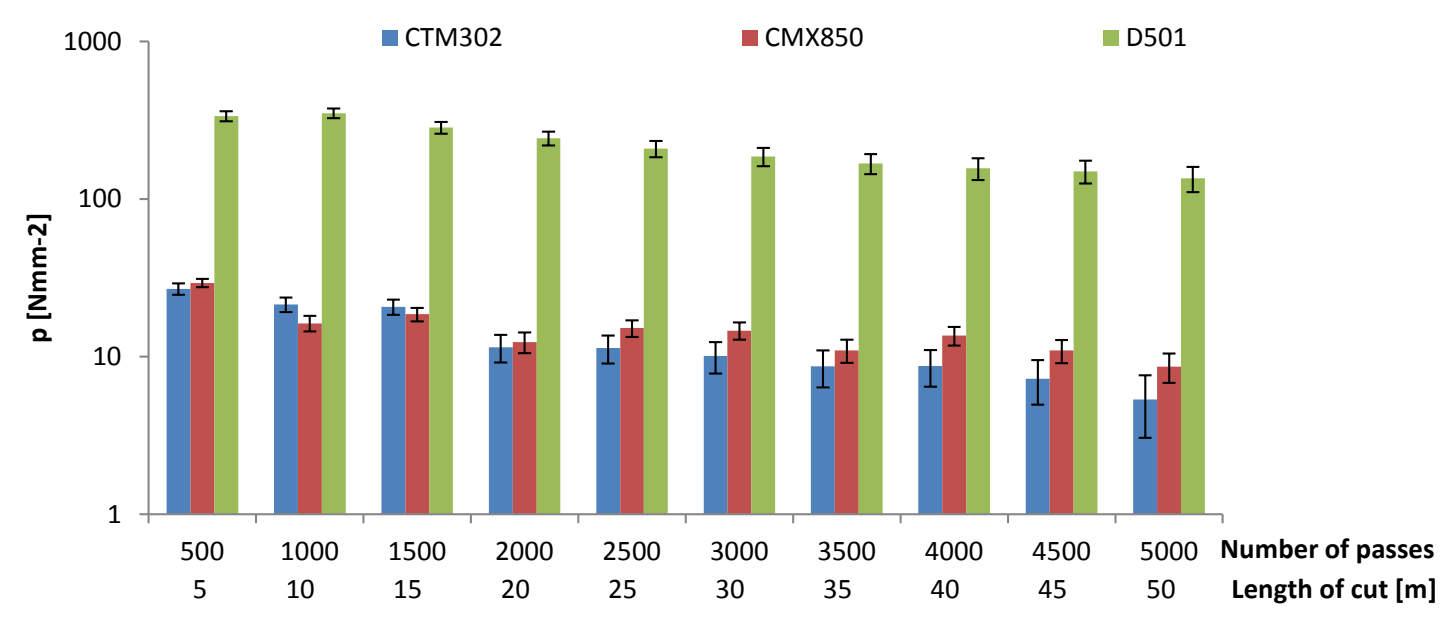

Fig. 21: Comparative graph showing the calculated contact pressures, on the vertical $Y$ axis in logarithmic scale.

\subsection{Micro wear/cutting performance of PCBN abrasive arrays against electroplated}

\section{CBN pads}

While polycrystalline diamond proved to have a similar wear progression for the two different grades PCD tested having both a metallic binder, the PCBN arrays were found to have different wear progression because of the different binder phases and CBN grain dimensions. In the case of high-CBN content array, the unworn PCBN abrasive edge is shown in Fig. a, where the white arrows indicate the initial sharpness of the abrasive edge, which has shown a $10 \%$ circa reduction in height edges at intermediate stages of 500 passes at $1 \mu \mathrm{m}$ depth of cut resulting in a total height reduction of $20 \%$ at the end of the test (Figs. $22 \mathrm{~b}-\mathrm{c}$ ). This wear progression is of the abrasive type and it probably was facilitated by the high thermal conductivity of the metallic binder that 
caused the heat to quickly be transferred outside the edge-workpiece interface, thus producing a constant abrasive wear with the increased number of passes (and consequently length of cut). The total flank wear from the beginning of the test to the end is of a total value of $20 \mu \mathrm{m}$, which represents only the $2 \%$ of the total theoretical stock of material removed on the shaft after 1000 passes.

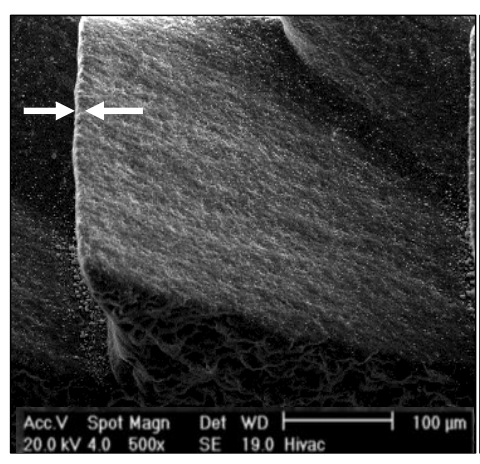

a)

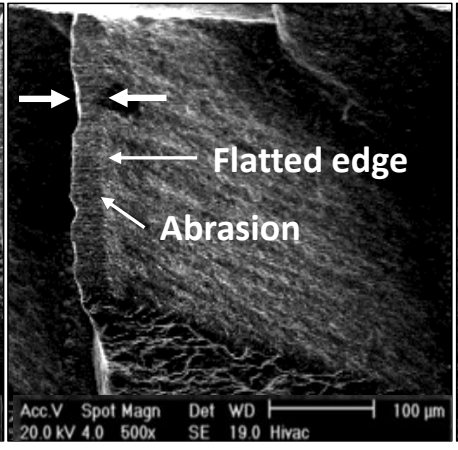

b)

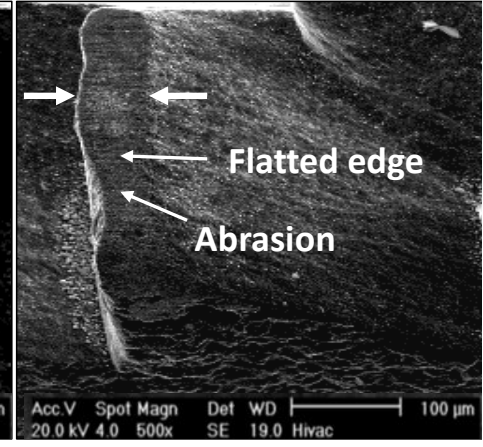

c)

Fig. 22: ESEM tilted view comparative imaging of the DBS900 in the wear test $(1 \mu \mathrm{m}$ depth of cut): a) before test, b) after 500 passes, c) after 1000 passes.

In the case of medium-CBN content array, a different wear progression has been found for the unworn area of the abrasive edge (Fig. 23a). Because of the repeated-cycle deformation mechanism previously mentioned, a crack formed causing the side edge to fracture (Fig. 23b); then, further macro-damage formed on the same abrasive edge possibly caused by the interrupted cycle deformation imposed on the material by its intermittent contact with the workpiece (Fig. 23c). 


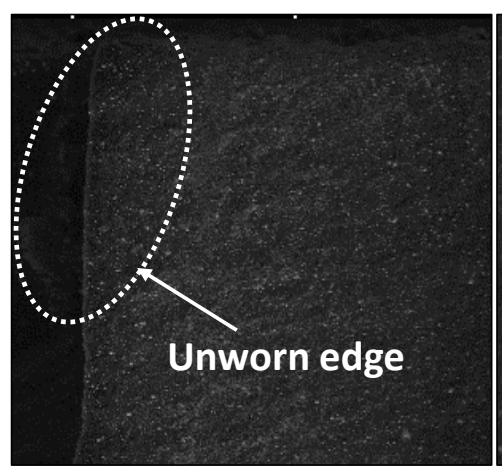

a)

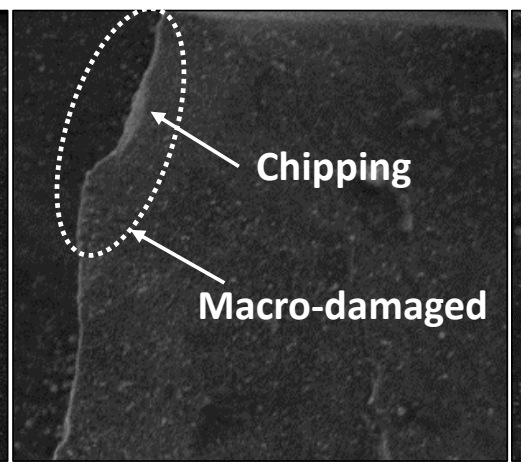

b)

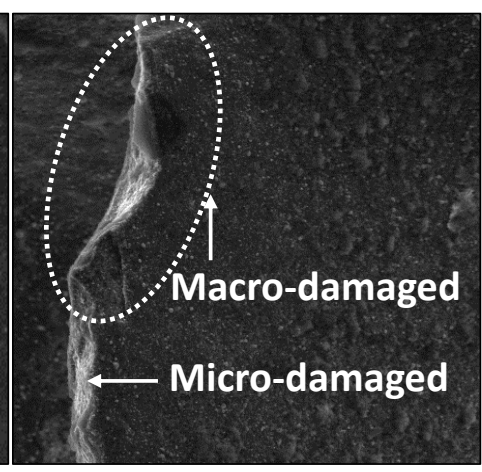

c)

Fig. 23: ESEM tilted view of the DBW85 during the wear test (1 $\mu \mathrm{m}$ depth of cut): a) before the test, b) after 500 passes, c) after 1000 passes.

The wear mechanism of the electroplated CBN B501 abrasive has proved to be similar to the purely metallic binder PCBN array; flank wear of the grit is the main phenomenon occurring: the height reduction for an average grit after 1000 passes is circa $40 \%$ of the grit height, (Fig. 24b); this proves that the wear progression is slower in the case of the laser generated PCBN arrays (20\% only reduction in height) if compared to CBN electroplated abrasives (40\% only reduction in height). The different wear characteristics identified after the same number of passes between the abrasive array DBS900 and the electroplated CBN abrasive is due to several reasons: (i) the abrasive edge geometry: because of its positive rake angle the edge can reduce the vibration during machining; (ii) the density of edges/grits in the same area: having less abrasives on the same area might force the taller abrasive to absorb all the impact and vibration of machining, causing a proportional flattening. 


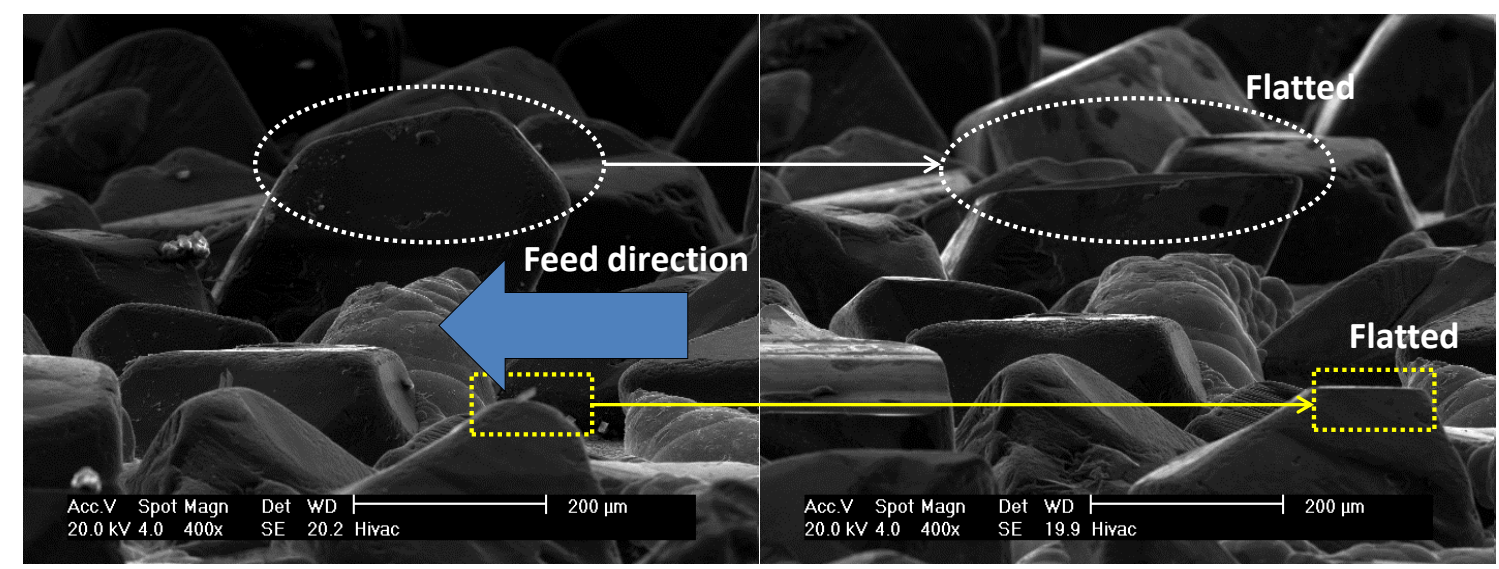

a)

b)

Fig. 24: ESEM micrographs showing some detail of the same selected microgrit unworn/worn on the electroplated CBN grain: a) before the test, unworn area b) after 1000 passes ( $1 \mu \mathrm{m}$ depth of cut) worn area.

Using the same procedure as previously mentioned for the case of PCD abrasive arrays/electroplated diamond, the contact pressures have been calculated; Table 3 includes the results for experimental contact area and the relative contact pressures respectively after 250 passes and 1000 passes in the case of the PCBN abrasives and electroplated CBN pads.

Table 3: Measured values of contact area of the micro-edge/grits with the shafts and the calculated contact pressures for the PCBN arrays and the electroplated diamonds.

\begin{tabular}{lllll}
\hline Specimen & $A_{250}\left[\mathrm{~mm}^{2}\right]$ & $A_{1000}\left[\mathrm{~mm}^{2}\right]$ & $p_{250}\left[\mathrm{~N}^{*} \mathrm{~mm}^{-2}\right]$ & $p_{f 1000}\left[\mathrm{~N}^{*} \mathrm{~mm}^{-2}\right]$ \\
\hline PCBN DBS900 & 0.007 & 0.017 & 53.14 & 48.93 \\
PCBN DBW85 & 0.007 & 0.017 & 209.8 & 99.45 \\
Electroplated & 0.032 & 0.035 & 104.3 & 92.28 \\
\hline
\end{tabular}


The slower wear progression of the PCBN array with pure metallic binder (DBS900) is shown in Fig. 25, where this is compared to the medium CBN-content (DBW85) whose resulting contact pressures proved to be higher than both the DBS900 and the B501. The saddle shape evident in the electroplated CBN (Fig. 25) is mainly due to a variation of grits height.

In the case of the purely metallic binder specimen (DBS900), the high thermal conductivity of CBN rapidly takes the heat away from the cutting zone [39], and this results in: lower contact pressures (Fig. 25), less softening of the material at the interface abrasive/workpiece and mainly flank wear as a typical wear progression mechanism. The presence of the metalloids B and Al in the medium-CBN content array (DBW85) makes the mechanical structure more brittle, but it also reduces the thermal conductivity of $\mathrm{CBN}$ by $50 \%$ [35], thus the heat concentrates in the shear zone producing higher contact pressures (Fig. 25), a favourable softening of the material (at the interface abrasive/workpiece) which reduces the flank wear on the abrasive edge, leaving fracturing as main wear mechanism.

As shown in the graph of pressure for the three specimens under test depicted in Fig. 25 , it is evident that the electroplated pad B501 worn out quicker than pure metallic binder specimen (DBS900) but slower than DBW85. The latter has in fact shown fracturing as main deformation mechanism (as previously demonstrated by ESEM analysis) which can explain the reason of very high contact pressures with the workpiece material during testing, and therefore it cannot be directly compared to the other two tested pads. A direct comparison between one of the two manufactured micro-cutting 
array and a benchmarked specimen was made possible especially thanks to similar wear (flattening) experienced between B501 and PCBN DBS900. In this regard, essential is the results of contact pressures measured during test and reported in Table 3-Fig. 25: the lower pressures of the micro-array (DBS900) against the electroplated specimen are the evidence of wear resistance property of this novel material.

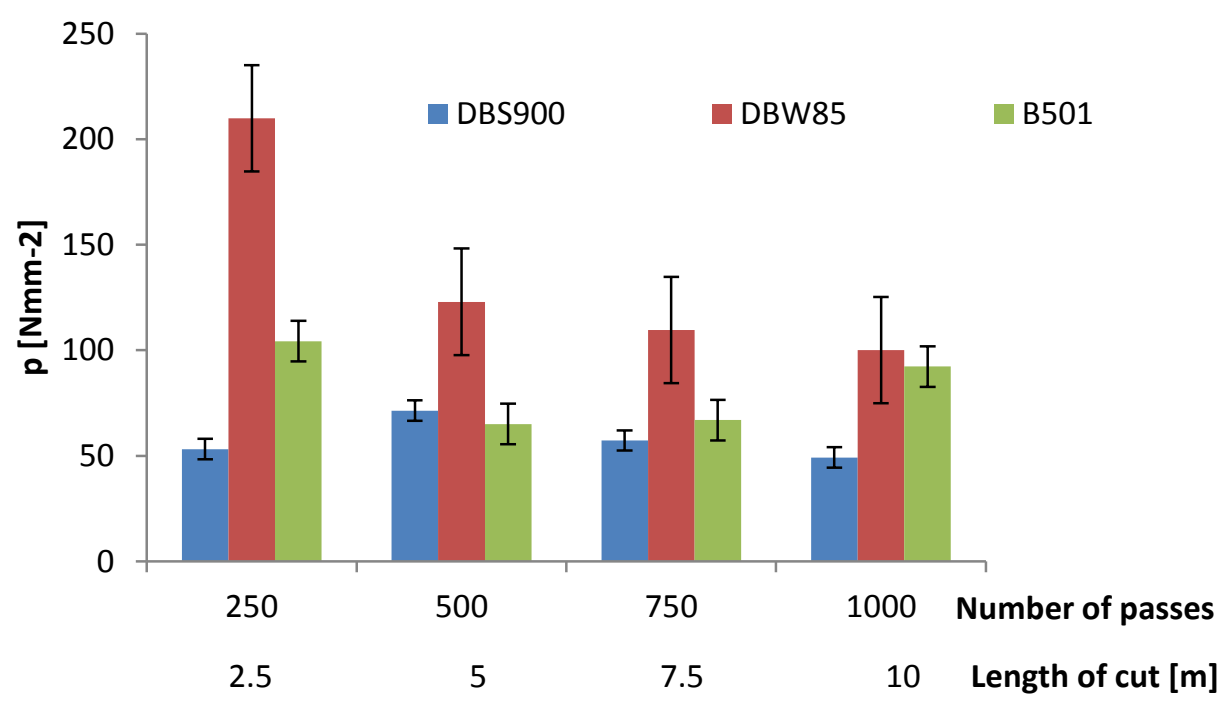

Fig. 25: Comparative graph showing the calculated contact pressures for the PCBN/electroplated CBN specimens.

\section{CONCLUSIONS}

The wear progression of PCD/PCBN micro-abrasive edges has been studied and benchmarked against electroplated diamond/CBN pads; the results are summarised in the following key points:

- For the PCD engineered abrasive micro-arrays, the size of diamond grain and binder percentage affect the wear performances. Regardless optimal edge tool 
geometry in testing, CTM302 coarse PCD grain showed slower wear (in terms of time to crack formation) when compared to the CMX850 fine grain PCD; in this respect, for $\mathrm{CTM} 302$ the length of cut leading to crack formation was approx. $33 \%$ longer than for CMX850. This behaviour could be caused by a thermal effect when testing the micro-structurally different PCD composites: an $80 \%$ mismatch of thermal expansion coefficient could possibly have resulted in higher internal stresses in the diamond composite with higher binder bulk volume percentage (CMX850) when compared to CTM302, leading the finer diamond grain size composite to fracture quicker. This confirms high wear resistance typical of the fine grain and the good shock resistance typical of the coarse grained PCD.

- For the PCBN DBW85 the presence of a medium-CBN (and the reduction of thermal conductivity) together with the metalloids binders produces higher contact pressures (when compared to DBS900) and causes fracturing of the engineered abrasive micro-arrays as main wear/failure mechanism. The PCBN DBS900 arrays have shown a flank wear of approx. $15 \%$ of the total height of the cutting edge, after a length of cut of $10 \mathrm{~m}$; this PCBN grade has proven to have slower wear progression and a lower trend-line of the contact pressures due to the quick heat transfer which caused mainly flank wear without cracking of the micro-edges.

- After a length of cut of $10 \mathrm{~m}$, the B501 electroplated abrasive has shown micro damaged grits with a flank flattening between $25 \%$ and $35 \%$ of the total grit 
height. This height flattening is circa double the value achieved for the PCBN arrays (15\%).

- Both PCD and PCBN abrasive arrays have shown higher wear resistance when benchmarked to the most used abrasive electroplated pads (D501, B501); the orderly micro-cutting edge arrays produced $70 \%$ lower contact pressures in comparison with the negative rake angle typical of the grits in the electroplated specimens. This being corroborated with the better wear performance proved that the engineered abrasive micro-cutting edges represent a step change in replacing the conventional electroplated pads (with stochastically distributed abrasives) for grinding/polishing operations.

The superior wear-resistant properties of micro-cutting arrays produced by pulsed laser ablation have been demonstrated via benchmarked grinding/cutting test of silicon dioxide rods. It has been demonstrated that the microstructural properties (binder percentage, abrasive dimension) are the main responsible of the wear performances. As expected, both of the diamond polycrystalline specimens containing metallic binders (mix grained and fine grained) have shown lower contact pressure with the workpiece when compared to a benchmark, therefore endorsing the possibility of introducing these micro-features in the generation of tools for advanced engineering applications. Polycrystalline cubic boron nitride arrays exhibited different wear behaviours in function of the type of binder. In particular, the specimen containing purely metallic binder (DBS900) has proved its wear-resistant characteristics when compared to a benchmark and to an array with no purely metallic binder (containing metalloids). 


\section{ACKNOWLEDGMENT}

The authors would like to acknowledge the support of the Centre of Doctoral Training of

The University of Nottingham and Element Six for their financial support.

\section{REFERENCES}

[1] Cook, M. W., and Bossom, P. K., 2000 "Trends and recent developments in the material manufacture and cutting tool application of polycrystalline diamond and polycrystalline cubic boron nitride," International Journal of Refractory Metals and Hard Materials, 18, pp. 147-152.

[2] Ismail, M. F., Yanagi, K., and Isobe, H., 2011, "Characterization of geometrical properties of electroplated diamond tools and estimation of its grinding performance," Wear, 271(34) pp. 559-564.

[3] Butler-Smith, P. W., Axinte, D. A., and Daine, M., 2011, "Ordered diamond micro-arrays for ultra-precision grinding-An evaluation in Ti-6AI-4V," Int. J. Mach. Tools Manuf., 51(1), pp. 54-66.

[4] Butler-Smith, P. W., Axinte, D. A., Pacella, M., and Fay, M. W., 2013, "Micro / nanometric investigations of the effects of laser ablation in the generation of micro-tools from solid CVD diamond structures," J. Mater. Process. Technol., 213, pp. 194-200.

[5] Pacella, M., Axinte, D. A., Butler-Smith, P. W., and Daine, M., 2014, "On the Topographical/Chemical Analysis of Polycrystalline Diamond Pulsed Laser Ablated Surfaces," Procedia CIRP, 13, pp. 387-392.

[6] Pacella, M., 2014, "Pulsed laser ablation (PLA) of ultra-hard structures: generation of damage-tolerant freeform surfaces for advanced machining applications," Ph.D thesis, http://eprints.nottingham.ac.uk/27730/1/Pacella\%20Manuela\%20PhD\%20Final\%20Thesis .pdf

[7] Butler-Smith, P. W., Axinte, D. A., and Daine, M., 2009, "Preferentially oriented diamond micro-arrays: A laser patterning technique and preliminary evaluation of their cutting forces and wear characteristics," Int. J. Mach. Tools Manuf., 49(15), pp. 1175-1184.

[8] Pacella, M., Axinte, D. A., Butler-Smith, P. W., Axinte, D. A., and M. W. Fay, 2014, "FIB/TEM/EELS micro/nanometric investigations of the effects of laser ablation on the diamond/binder structure in polycrystalline diamond composites," J. Mater. Process. Technol., 214(5), pp. 1153-1161.

[9] Zawada-Tomkiewicz, A., 2011, "Analysis of surface roughness parameters achieved by hard turning with the use of PCBN tools," Est. J. Eng., 17(1), p. 88. 
[10] Tan, N., Liu, C. J., Li, Y. J., Dou, Y. W., Wang, H. K., Ma, H., Kou, Z. L., and He, D. W., 2010, "Characterization of polycrystalline cBN compacts sintered without any additives," Eur. Phys. J. Appl. Phys., 53(1), p. 11501.

[11] Halpin, T., Byrne, G., Barry, J., and Ahearne, E., 2009, "The performance of polycrystalline cubic boron nitride tools in continuous, semi-interrupted, and interrupted hard machining," Proc. Inst. Mech. Eng. Part B J. Eng. Manuf., 223(8), pp. 947-953.

[12] Kawasegi, N., Sugimori, H., Morimoto, H., Morita, N., and Hori, I., 2009, "Development of cutting tools with microscale and nanoscale textures to improve frictional behavior," Precis. Eng., 33(3), pp. 248-254.

[13] Sharif Uddin, M., Seah, K. H. W., Li, X. P., Rahman, M., and Liu, K., 2004, "Effect of crystallographic orientation on wear of diamond tools for nano-scale ductile cutting of silicon," Wear, 257(7-8), pp. 751-759.

[14] Zareena, R., and Veldhuis, S. C., 2012, "Tool wear mechanisms and tool life enhancement in ultra-precision machining of titanium," J. Mater. Process. Technol., 212(3), pp. 560-570.

[15] Mao, W. L., Mao, H., Eng, P. J., Trainor, T. P., Newville, M., Kao, C., Heinz, D. L., Shu, J. , Meng, Y., and Hemley, R. J., 2003, "Bonding changes in compressed superhard graphite.," Science, 302(5644), pp. 425-427.

[16] Gogolinsky, R., 1998, "Nano-sclerometry measurements of superhard materials," Diagnostic Mater., 6(64), pp. 30-43.

[17] Neale, M. J. and Gee, M., 2001, Guide to wear problems and testing for industry, William Andrew Publishing, New York, NY, USA.

[18] Hutchings, I. M., 1992, Tribology friction and wear of engineering materials, Oxford, UK.

[19] Wong, C. J., 1981, "Fracture and wear of diamond cutting tools," J. Eng. Mate., 103(4), pp. 341-345.

[20] Sen, P. K., Cook, M. W., and Achilles, R. D., 1998, "Various diamond cutting tool materials for the machining of HPL Wood Flooring," IDA Superabrasives Conference.

[21] Hwang, T. W., Evans, C. J., and Whitenton, E. P., 2000, "High speed grinding of silicon nitride with electroplated diamond wheels, part 1: Wear and wheel life", J. Manuf. Sci. E., 122(1), pp. 32-41.

[22] Hwang, T. W., and Evans, C. J., 2014, "High Speed Grinding of Silicon Nitride With Electroplated Diamond Wheels , Part 2: Wheel Topography and Grinding," J. Manuf. Sci. E., 122.

[23] Moore, D. F., Principle and application of tribology, Pergamon, Oxford, 1975.

[24] Shaw, M. C. Metal cutting principles. Oxford University Press, Oxford, 1984. 
[25] Carolan, D., Petrović, M., Ivanković, A., and Murphy, N., 2010, "Fracture Properties of PCBN as a Function of Loading Rate and Temperature," Key Eng. Mater., 452-453, pp. 457-460.

[26] Element Six, 2013, "PCBN properties and applications," http://www.e6.com/wps/wcm/connect/e6_content_en/home/materials+and+products/pcbn.

[27] Huang, H., Yin, L., and Zhou, L., 2003, "High speed grinding of silicon nitride with resin bond diamond wheels," J. Mater. Process. Technol., 141, pp. 329-336.

[28] Dawson, T. G., and Kurfess, T. R., 2004, "Modeling the Progression of Flank Wear on Uncoated and Ceramic-Coated Polycrystalline Cubic Boron Nitride Tools in Hard Turning" J. Manuf. Sci. E., 128(1), pp. 104-109.

[29] Kahn, H., Ballarini, R., and Heuer, A., 2004, "Dynamic fatigue of silicon," Curr. Opin. Solid State Mater. Sci., 8(1), pp. 71-76.

[30] Huang, Y., Chou, Y. K., and Liang, S. Y., 2006, "CBN tool wear in hard turning: a survey on research progresses," Int. J. Adv. Manuf. Technol., 35(5-6), pp. 443-453.

[31] Goel, S., Luo, X., Reuben, R. L., and Pen, H., 2012, "Influence of temperature and crystal orientation on tool wear during single point diamond turning of silicon," Wear, 284-285, pp. 65-72.

[32] Chou, Y. K., and Evans, C. J., 1999, "Cubic boron nitride tool wear in interrupted hard cutting," Wear, 225-229, pp. 234-245.

[33] Miess, D., and Rai, G., 1996, "Fracture toughness and thermal resistance of polycrystalline diamond compacts," J. Manuf. Sci. E., 209(1-2), pp. 270-276.

[34] Akaishi, M., Ohsawa, T., and Yamaoka, S., 2006, "Synthesis of Fine-Grained Polycrystalline Diamond Compact and Its Microstructure," J. Am. Ceram. Soc., 74, no. 1, pp. 5-10.

[35] Edwards, R., 1993, Cutting tools, The institute of materials.

[36] Che, D., Han, P., Guo, P., and Ehmann, K., 2012, "Issues in Polycrystalline Diamond Compact Cutter-Rock Interaction From a Metal Machining Point of View-Part I: Temperature, Stresses, and Forces," J. Manuf. Sci. E., 134(6).

[37] Chen, F., Xu, G., Ma, C., and Xu, G., 2010, "Thermal residual stress of polycrystalline diamond compacts," Trans. Nonferrous Met. Soc. China, 20(2), pp. 227-232.

[38] Bertagnolli, K., and Vale, R., 2000, "Understanding and controlling residual stresses in thick polycrystalline diamond cutters for enhanced durability," Proceeding of international techical conference on diamond, cubic boron nitride and their applications.

[39] Bayer, R. G., 2002, Wear analysis for engineers, HNB Publishing. 